\title{
MINA LAS TURQUESAS: LAPIDARIA, SECUENCIA ALFARERA PREHISPÁNICA E INTERRELACIONES CULTURALES EN UN ESPACIO INTERNODAL DEL DESIERTO DE ATACAMA, CHILE
}

\author{
LAS TURQUESAS MINE: LAPIDARY, POTTER PRE-HISPANIC \\ SEQUENCE AND CULTURAL INTERRELATIONSHIPS IN AN \\ INTERNODAL SPACE FROM THE ATACAMA DESERT, CHILE
}

Carlos González Godoy ${ }^{1}$ Catherine Westfall ${ }^{2}$ y Carmen Castells Schencke 3

\begin{abstract}
Resumen
En este artículo se presenta la secuencia ocupacional alfarera de la Mina Las Turquesas, emplazada en El Salvador, comuna de Diego de Almagro, discutiendo sus aportes al conocimiento de la minería lapidaria prehispánica y sobre las probables interrelaciones entre las manifestaciones culturales alfareras circumpuneñas y del valle de

Copiapó, caracterizando sus particulares ocupaciones internodales dentro del desierto de Atacama. Igualmente, se postulan vinculaciones de este sitio con rutas camineras locales y con el Qhapaq Ñan longitudinal. También se entregan fechados absolutos inéditos de la Mina Las Turquesas y del oasis de Finca de Chañaral, para discutir determinadas interacciones sociales. Finalmente, y en base al sitio Mina Las Turquesas, se plantean las singularidades socioculturales de la zona en estudio (comuna de Diego de Almagro), ubicada en el Desierto Meridional de Atacama.
\end{abstract}

Palabras claves: Minería no metalífera - interacciones culturales redes caravaneras - prehistoria alfarera. article presents the occupational pottery sequence of the Las Turquesas Mine, located in El Salvador, Diego de Almagro commune, discussing its contributions to the knowledge of the pre-hispanic lapidary mining and the probable interrelations between the cultural manifestations pottery circumpuneña and of the Copiapo valley, with

the purpose to characterize its particular intermodal occupations within the Atacama Desert. Likewise, linkages of this site are posited with local road routes and the longitudinal Qhapaq Nan. There is also unpublished absolute dated from the Las Turquesas Mine and Finca of Chañaral oasis, to discuss certain social interactions. Finally, based on the site Las Turquesas Mine, as an analytical focal point, the sociocultural singularities of the area under study (Diego de Almagro commune), located in the Southern Atacama Desert, are proposed.

Keywords: Non-metalliferous mining - cultural interactions - caravan networks - prehistory pottery.

Recibido: abril 2016. Aceptado: abril 2017.

\author{
En memoria del historiador y amigo \\ Gonzalo Sotomayor Cabeza \\ $(17.02 .1974 / 3.03 .2016)$
}

\section{* Introducción}

Los trabajos arqueológicos efectuados en el sitio Mina Las Turquesas (Sal-25, coordenadas UTM WGS 84: 444049 E / $7096086 \mathrm{~N}$; en adelante MLT), ubicado en la comuna de Diego de Almagro, en el extremo noreste de la región de Atacama, han llamado la atención respecto a las probables interrelaciones, contactos e intercambios entre las comunidades circumpuneñas occidentales y del valle de Copiapó. En este sitio se han registrado ocupaciones desde aproximadamente el $500 \mathrm{AC}$, con grupos portadores de cerámica Los Morros y Loa Café Alisado, hasta testimonios históricos indígenas (Uribe et al. 2004) y subactuales (Castells et al. 2010a), descartando la exclusiva filiación inca del sitio definida originalmente por Iribarren (1972-1973). Esta mina lapidaria y centro artesanal se emplaza a $2830 \mathrm{msnm}$ en el cerro Indio Muerto de El Salvador, manifestando una acentuada presencia de mineros-caravaneros atacameños, como también de expresiones culturales Ánimas. De igual modo concentra objetos, materias primas y productos transportados desde otros puntos del desierto, valles y costa (González y Westfall 2005, 2008; González et al. 2010; Westfall y González 2010). Estos antecedentes dejan entrever la existencia de rutas caravaneras preincaicas en el desierto meridional de Atacama, que el Inka con posterioridad unifica bajo

1 Instituto de Investigación en Ciencias Sociales y Educación, Universidad de Atacama, Copiapó, CHILE. Email: carlos.gonzalezg@uda.cl

2 Máster en Historia y Gestión del Patrimonio Cultural. Investigadora Independiente, CHILE. Email: catherine.westfall@gmail.com

3 Conservadora. Investigadora independiente, CHILE.Email: ccastells@me.com 


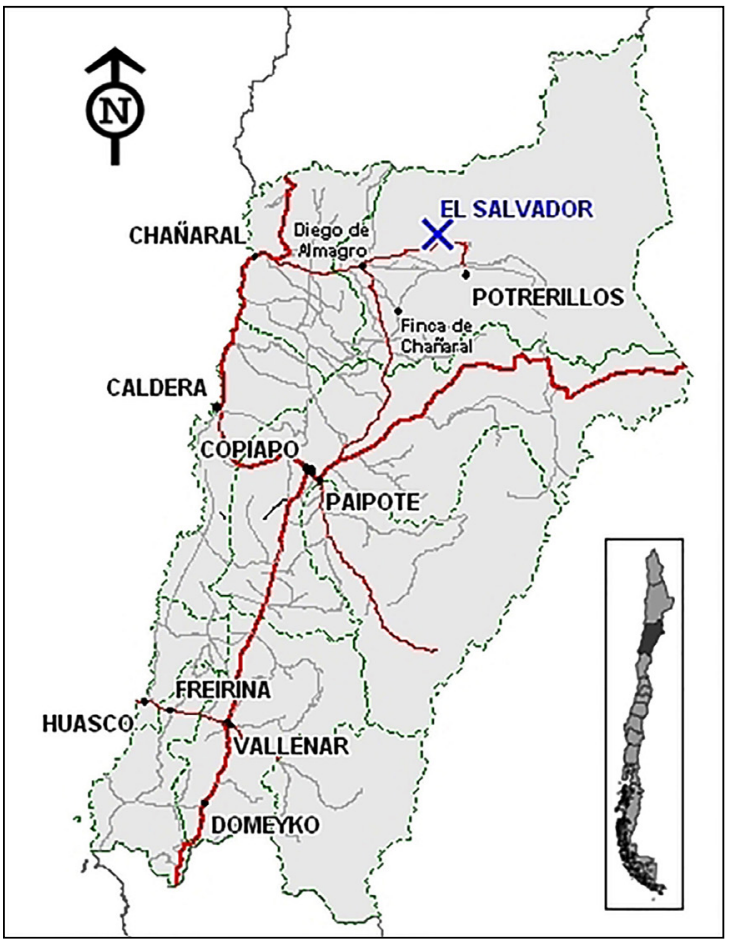

Figura 1. El Salvador (MLT), Diego de Almagro y Finca de Chañaral, región de Atacama.

sus lineamientos culturales, rituales, sociales y políticos, si bien toma como pauta los caminos locales precedentes. En consecuencia, nuestro trabajo analiza la información arqueológica del sitio MLT, presentando su secuencia ocupacional, particularidades, aportes al conocimiento minero lapidario y sus contribuciones para reconstruir los procesos sociales prehispánicos de la comuna de Diego de Almagro, Despoblado de Atacama. Estos resultados se complementan con información arqueológica del territorio comunal, entre ellas expresiones viales prehispánicas, como el Camino del Inka. La comuna en cuestión se ubica a $149 \mathrm{~km}$ al noreste de la ciudad de Copiapó, contando con una superficie total de $18.664 \mathrm{~km} 2$, en el desierto de Atacama (Figuras 1 y 2). Junto con ello, presentamos dataciones absolutas inéditas de la MLT logradas por nuestro equipo, al igual que del oasis de Finca de Chañaral (ver Figura 2), obtenidas en 2010 por el proyecto Qhapaq Nan Chile, ${ }^{4}$ las cuales nos ayudarán

4 Fechas publicadas en este artículo gracias al Ord. $N^{\circ} 3927$ del Consejo de Monumentos Nacionales. Se generaron en el marco de la postulación del tramo Qhapaq Ñan-Sistema Vial Andino, Chile, a la Lista de Patrimonio Mundial de la UNESCO; en adelante Proyecto Qhapaq Ñan-CMN. El primer autor participó como coordi-

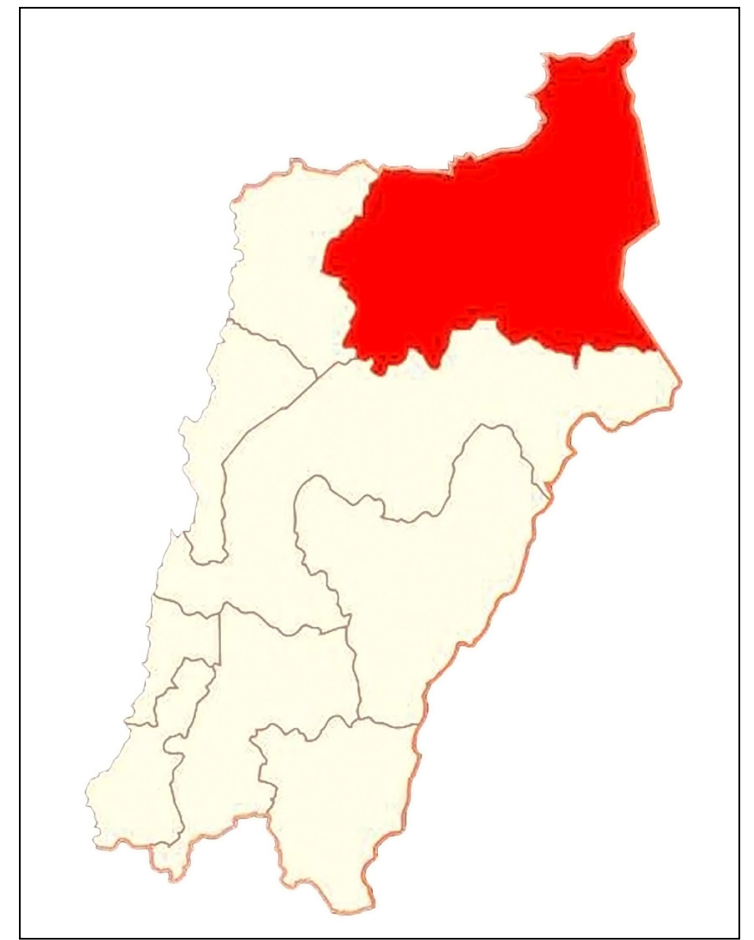

Figura 2. Comuna de Diego de Almagro (en gris), al noreste de la región.

a contextualizar la narrativa temporal del artículo y las ocupaciones prehispánicas. Valga precisar que definimos este espacio como desértico e internodal, cuyas especificaciones culturales serán analizadas en este trabajo.

\section{* Desierto y prehistoria alfarera en Diego de ALMAGRO}

Al comenzar nuestras investigaciones en la comuna de Diego de Almagro, observamos una frecuente desvinculación de sus desarrollos culturales prehispánicos del área circumpuneña, pese a opiniones y trabajos significativos que han manifestado lo contrario (Martínez 1990, com. pers. 2013; Núñez 1987, 1991; Núñez y Dillehay 1995). Por su parte, Nielsen (2008: 3) delimita los Andes circumpuneños de la siguiente manera: "me refiero a las tierras altas de las provincias de Catamarca, Salta y Jujuy en el Noroeste argentino, de la Región de Antofagasta

nador de Atacama en la Línea Arqueología en el equipo del Departamento de Antropología, Universidad de Chile (2009-2010), en el desarrollo del aludido proyecto. Gran parte de estas fechas fueron publicadas por Uribe y Sánchez (2016: 566-567). 
en el Norte de Chile ${ }^{5}$ y los Departamentos de Potosí y Tarija en el Suroeste boliviano". De esta forma, se obvian los aportes culturales del noreste de la región de Atacama, restando información para comprender la integralidad de las ocupaciones prehispánicas, como de los procesos de movilidad prehispánica y de las diversas espacialidades presentes a lo largo del tiempo en este territorio desértico. Esto no implica unificar por completo la comuna de Diego de Almagro a los desarrollos circumpuneños occidentales, sino más bien entender la existencia de algunos elementos de estas características y sus interacciones sociales con las expresiones culturales del Despoblado de Atacama.

Asimismo, se ha considerado por convención dentro de los estudios arqueológicos que las actuales regiones chilenas de Atacama y Coquimbo, forman en conjunto lo que se conoce como "norte semiárido" o "Norte Chico", que comprende los valles transversales desde la región de Atacama al sur, a diferencia del "Norte Grande", que concluiría en el límite sur, político, de la región de Antofagasta. Un ejemplo de esta situación lo encontramos en un trabajo de Iribarren y Bergholz (1972-1973) sobre el Camino del Inka, realizado al norte de Copiapó en pleno desierto de Atacama, en el que mencionan que su investigación se efectúa en un "sector del norte chico". En forma paralela, se han asimilado tradicionalmente para ambas regiones los mismos desarrollos culturales prehispánicos. Incluso se replica la secuencia cultural prehispánica maestra del valle de Copiapó para toda la región de Atacama (Niemeyer 1994; Niemeyer et al. 1998). Al contrario, en el trabajo de Troncoso y Pavlovic (2013) se consideran las comunidades alfareras del norte semiárido, pero solo a contar del valle de Copiapó hacia el sur, detallando sus diferencias. Esto pone de manifiesto que los procesos sociales prehispánicos no se corresponden con los límites geopolíticos contemporáneos (Castro et al. 2016:241)

Desde el punto de vista geográfico, la Puna Salada en nuestro país se extiende según Troll (1958; citado en Núñez y Dillehay 1995:34) hasta las cercanías de Copiapó. Lo anterior también se suma a las determinaciones de Chong (2012: 28), que ubica arbitrariamente el término del norte de Chile a la altura de los $27^{\circ} \circ 0^{\prime}$ de latitud Sur, al septentrión de Copiapó. Coincidentemente, desde

5 El subrayado es nuestro. la perspectiva geológica, entre los $27^{\circ}$ y los $33^{\circ}$ de latitud Sur se reconocen dos provincias tectónicas con estilos estructurales distintos pero convergentes, correspondientes al Norte Chico chileno (Moscoso y Mpodozis 1988: 163). Por consiguiente, desde el ámbito geohistórico el noreste de la región de Atacama no puede desligarse en términos geográficos, históricos y culturales de los desarrollos sociales prehispánicos del desierto de Atacama (González y Westfall 2005, 2008; González et al. 2010), aunque tampoco totalmente del norte semiárido. De allí que nos resulte inapropiado incluir la totalidad de nuestra área de trabajo como integrante del norte semiárido, tanto geográfica como culturalmente hablando, si bien presenta evidencias culturales de esa región natural.

En este espacio se gestaron probables interrelaciones preincaicas entre las sociedades Molle, Ánimas y Copiapó, con las poblaciones provenientes de la cuenca del río Loa y San Pedro de Atacama, considerando en esta discusión el sello atacameño de la MLT, principalmente durante el Intermedio Tardío y la precedente ocupación Ánimas, que se encuentra en un segundo lugar en el sitio (González y Westfall 2005, 2008; Westfall y González 2010). Con estas observaciones apuntamos a enfatizar la constante interacción desarrollada en el tiempo en un vasto desierto y oasis (Nielsen 2008). Unidos a las condiciones geográficas desérticas, se visualizan recursos (por ejemplo, mineros) y la producción de cultivos en espacios acotados como oasis y aguadas, en verdaderos "bolsones fértiles" al decir de Nielsen (2008: 4). El oasis de Finca de Chañaral, a más de 50 km en línea recta del cerro Indio Muerto, es testimonio de aquello, con terrazas fluviales que no solo permitieron la instalación de asentamientos, sino también habilitar, seguramente, espacios con cultivos en épocas alfareras, tal como lo sustentan hojas líticas de palas agrícolas e instrumentos de molienda, registrados por nuestro equipo en el oasis.

Del mismo modo, cuando nos referimos a que nuestra atención está en el desierto meridional de Atacama y, concretamente, en la actual comuna de Diego de Almagro, conceptualizamos este territorio, siguiendo a Giménez y Héau Lambert (2007: 11), como un espacio apropiado, ocupado y dominado por acción de un grupo social (o varios), donde reproduce(n) y satisface(n) sus necesidades esenciales, de orden material y simbólico. Sin embargo, no hay que olvidar la dimensión multiescalar del 


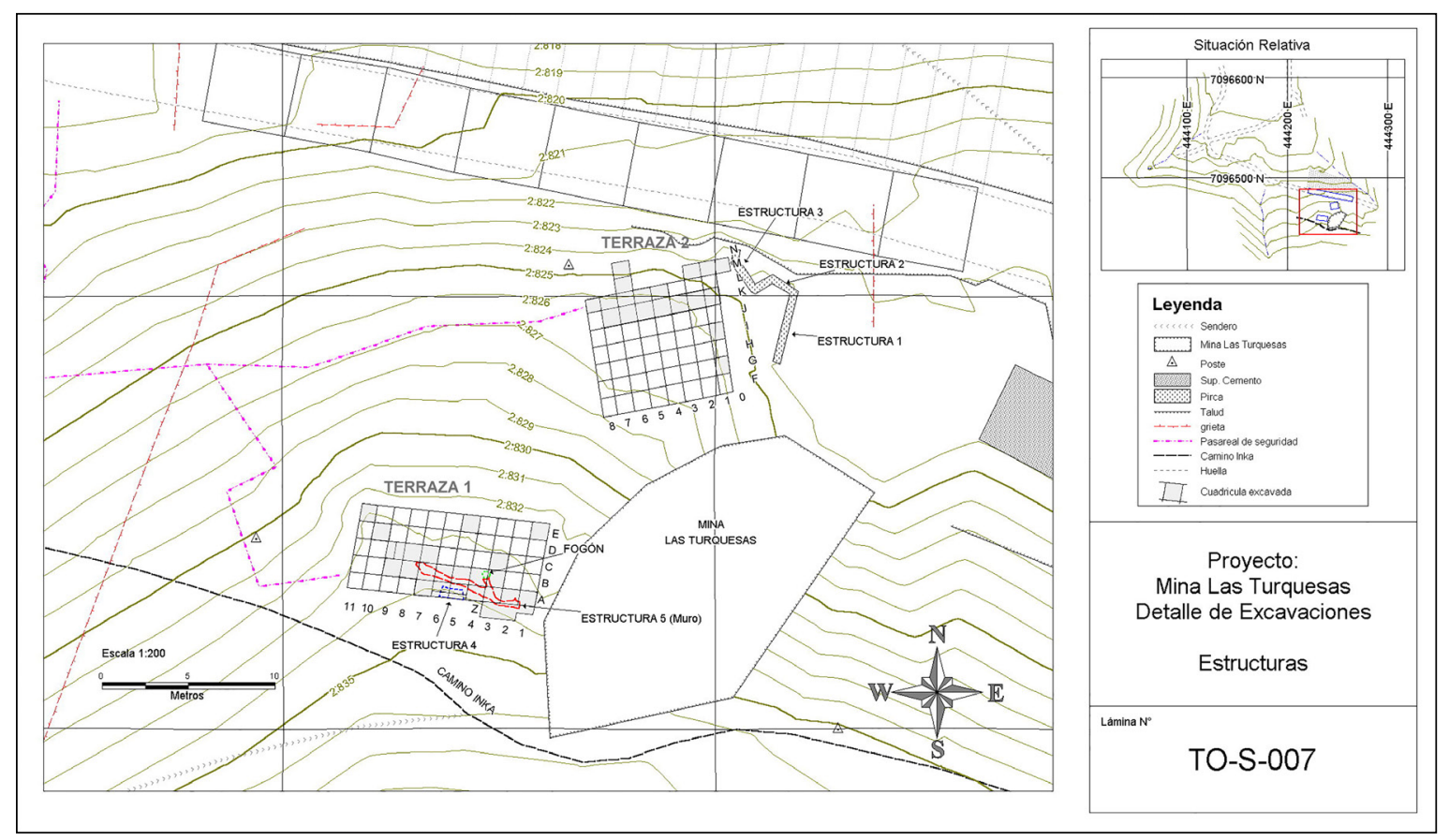

Figura 3. Plano de las excavaciones en la MLT y detalle del camino inca asociado.

territorio, considerando distintos niveles y sociedades, incluso desde una perspectiva local (Giménez y Héau Lambert 2007: 12), tal como acontece en nuestra área de trabajo. Igualmente, concebimos el desarrollo cultural prehispánico de la comuna desde una dimensión geohistórica (Braudel 2002) e internodal. ${ }^{6}$ Entendiendo por este último concepto un área entre asentamientos con altas densidades de población (Nielsen 2006: 34). En nuestro caso comprende un elongado espacio entre los nodos de San Pedro de Atacama por el norte y el valle de Copiapó por el sur, pero concentrándonos analíticamente entre el límite norte de la comuna y el sur en Tres Puntas. Por el oeste, limitamos con el espacio previo a la localidad de El Salado, mientras que al este con Argentina (Figura 2).

6 Mattozzi (2014: 93-94), siguiendo a Braudel (2002), define la geohistoria como la convergencia analítica basada "en la operación de reconstruir e interpretar los hechos sociales históricos, contextualizados en un entorno y en un territorio gracias a la aplicación intensiva de operaciones cognitivas espaciales".

\section{^ Reconstrucción prehispánica alfarera EN LA MLT}

Este sitio minero lapidario se emplaza en la ladera sureste y en la parte superior de la quebrada Las Turquesas, en el cerro Indio Muerto de El Salvador. Comprende actualmente una mina de más de $30 \mathrm{~m}$ de largo, dos socavones, un pique angosto derrumbado, avances individuales de galerías internas, escalera tallada en roca y un sector inmediato con testimonios de actividad minera lapidaria, artesanal (elaboración de cuentas de collar líticas y de conchas, como de figurillas de piedras) y habitacional, casi por completo prehispánicos, concentrados en dos terrazas artificiales ( 1 y 2 ), unidas por un talud, en una superficie de $1750 \mathrm{~m} 2$. En estas terrazas y en el talud se efectuaron recolecciones superficiales sistemáticas, al igual que en una huella subactual adyacente y en un talud bajo ella. Las excavaciones, realizadas por medio de cuadrículas de $1 \mathrm{~m} 2$, se concentraron en ambas terrazas. En la superior (1), con una superficie de $58 \mathrm{~m} 2$, se trabajaron 24 cuadrículas y en la terraza inferior (2), con una superficie de $66 \mathrm{~m} 2$, se excavaron 19 unidades (Figura 3). La guía 
inicial de intervención fue un análisis superficial de fósforo (P) aplicado en todas las cuadrículas proyectadas (Castells et al. 2o10b), para optimizar el acotado tiempo del que disponíamos, debido a la subsidencia minera del sector, las grietas presentes y los continuos derrumbes, por la cercanía del cráter artificial de la gran minería del cobre, generado desde 1959 a la fecha en el cerro Indio Muerto.

Corresponde a una mina lapidaria porque estuvo dedicada al trabajo de extracción de turquesas, otros minerales y arcillas. Lo anterior se confirmó por análisis mineralógicos destructivos y no destructivos de Difracción y Fluorescencia de Rayos X de 13 muestras del sitio, provenientes de ambas terrazas e interior mina, entre ellas de trozos de mineral, preforma de cuenta (cuadrícula M2, nivel 16, limpieza de perfil) y figurilla ornitomorfa (cuadrícula $K_{3}$, nivel 6). Estos análisis fueron efectuados en el laboratorio de geología de División Salvador de Codelco (Novajas 2004). El análisis contempló otras cinco muestras de sitios del cerro Indio Muerto: Sal 6-7-8, Sal 9 y Sal-27 (Cementerio Las Turquesas) (González y Westfall 2008).7 En la MLT prevalece la turquesa y la brochantita, encontrándose moscovita en dos muestras (fragmento de roca y preforma de cuenta), un mineral filosilicato que presenta tonalidades verdes. En las arcillas se identifica la caolinita (figurilla).

En la terraza superior (1) se desarrollaron trabajos de limpieza (Rees 1999) de trozos de turquesas y minerales de distintas dimensiones, producto de la reducción de nódulos y núcleos, con un predominio de fragmentos de $2 \mathrm{~cm},{ }^{8}$ preferentemente en un espacio delimitado por un muro pircado simple y rústico con bloques naturales, bajo (o,40 $\mathrm{m}$ de altura y $0,44 \mathrm{~m}$ de ancho) y transversal de más de $6 \mathrm{~m}$ de largo (Figuras 3 y 4), a modo de cancha de chancado (estructura 5), relacionada con el Intermedio Tardío. Además, se preparaban perforadores y microperforadores líticos sobre rocas silíceas; en esta terraza se obtuvieron 14 ejemplares (Contreras 2004). Se agrega una preforma de un pendiente, una piedra aparentemente para pulir y una pequeña punta de proyectil triangular pedunculada con aletas, entre otras evidencias de trabajo

7 Como referencia se agregó el análisis de una cuenta lítica de un collar de San Pedro de Atacama (Colección Museo Fonck).

8 Están pendientes análisis líticos que detallen la cadena operativa lapidaria del sitio (sensu García-Albarido 2007). lítico (núcleos y derivados de núcleos). De igual forma, se ubicaron puntuales actividades domésticas: fogón en cubeta; trozos y espículas de carbón dispersos; semillas; huesos de camélidos; entre otros. También se registraron restos textiles como torzales, cabos, vellones, vellón con piel y sogas (Cases 2004).

Destaca la recuperación de 208 fragmentos cerámicos del Formativo, Período Medio atacameño y Ánimas, Intermedio Tardío atacameño, especialmente inicial, y en menor número Tardío e Histórico (Uribe et al. 2004). Por su parte, las excavaciones en este sector alcanzaron una potencia estratigráfica de alrededor de 0,87 m, detectándose en la unidad E11 una letrina histórica de 1955 y 1956 (fechas de periódicos hallados), que disturbó los depósitos prehispánicos y, a su vez, entregó valiosa información, gracias al análisis de coprolitos humanos (Castells et al. 2010a). Los trabajos comprobaron la vinculación de la estructura 4 (Figura 3) con la ocupación del Intermedio Tardío. Consistía en un pequeño muro pircado simple de refuerzo, rústico, que empleó bloques naturales, con $0,47 \mathrm{~m}$ de alto y o,40 $\mathrm{m}$ de ancho, y una prolongación de más de $1 \mathrm{~m}$.

En la terraza inferior (2) se observó igualmente la reducción preferente de trozos de turquesa, la confección de perforadores y microperforadores líticos sobre mayoritarias rocas silíceas (preformas y finiquitados, con 504 ejemplares) y adornos (cuatro preformas de colgantes, tres colgantes terminados y preformas de cuentas; 16 trozos con pulimento), dos cuchillos, tres cepillos, dos percutores-martillos, siete puntas de proyectil (seis son triangulares pedunculadas con aletas y una triangular de base plana), una mano de moler, dos cuentas finiquitadas con perforación bicónica, núcleos y derivados de núcleos (Contreras 2004). Conjuntamente, se identificaron restos textiles como torzales, vellones, cabos, cordeles, anudados y sogas (Cases 2004). En esta terraza se apreció un acentuado uso habitacional del espacio, con actividades de combustión dispersas y un $93,1 \%$ del total del número de especímenes identificados por taxón (NISP) de la colección zooarqueológica (Velásquez 2004). Asimismo, se obtuvieron 1379 fragmentos cerámicos adscritos al Formativo, Período Medio atacameño y Ánimas, Intermedio Tardío atacameño -con la mayor presencia en el sitio-, Tardío e Histórico en baja proporción (Uribe et al. 2004). Las ocupaciones en esta terraza se presentaban diferenciadas, pero 
contiguas, en un lapso prolongado de tiempo, registrando las excavaciones una potencia estratigráfica que alcanzó los 2,60 m. Lamentablemente, el sector con mayor profundidad ocupacional de la terraza 2 (cuadrículas Mo, M1 y M2), fue cortado por un camino secundario en tiempos subactuales (Figura 5). En cuanto a las estructuras 1, 2 y 3 (ver Figura 3), atañen a avances mineros subactuales, adyacentes a la MLT.

De acuerdo a la única recolección intensiva que efectuamos al interior de la mina, ${ }^{9}$ en un espacio de $4 \mathrm{~m} 2$ (Figuras 6 y 7), se observó un depósito ocupacional colapsado y otros derrumbes, con una serie de evidencias prehispánicas (Westfall y González 2010), constatándose: limpieza de turquesa y de otros minerales; elaboración de perforadores; núcleos y derivados de núcleos; probables instrumentos para el pulido de cuentas (trozo cilíndrico de madera y piedra angosta y lisa); restos textiles como torzales, cordeles, cabos, anillado doble torsión, entre otros, vinculados, según parece, a la extracción y reparación de instrumental minero (Cases 2004); tres ceramios completos del tipo Dupont (ver Figura 7); fragmentos pirograbados de calabazas, un contenedor y otros fragmentos reparados de cucurbitáceas; cestería; fruto y semillas de Capsicum sp., inflorescencias de Typha sp. (totora) (Belmar y Quiroz 2004); y 139 fragmentos cerámicos del Formativo, Período Medio atacameño y Ánimas, Intermedio Tardío atacameño, y en menor número Tardío e Histórico (Uribe et al. 2004). Indudablemente, lo reducido de la muestra no representa la realidad de las acciones prehispánicas efectuadas al interior de la mina.

Las evidencias arqueológicas recuperadas de la MLT respaldan la existencia de materias primas, objetos y productos trasladados desde distintos y distantes ambientes, por medio del accionar caravanero y de contactos e intercambios con diversas comunidades. Consisten en: restos textiles distintivos de mineros-caravaneros, que emplearon fibras de camélidos, vegetales -entre ellos algodón-, pelo humano y chinchilla (Cases 2004); cestería en espiral simple (Prado 2004); objetos de madera (mangos para perforadores líticos, trozo cilíndrico, tortera, agujas, instrumentos activos para hacer fuego, cierres de bolsas, astiles, espinas de Prosopis sp., ganchos

9 Por las peligrosas condiciones del interior de la mina, tampoco fue posible actualizar topográficamente el plano de la MLT. de atalaje, entre otros) (De Ugarte et al. 2010); productos agrícolas como quínoa, maíz, madi, zapallo, ají, poroto y calabaza, y otras especies vegetales de oasis y ambientes lacustres, en especial el chañar (Belmar y Quiroz 2004); conchas del Pacífico, principalmente de Mytilidae y Pectinidae, utilizadas en su mayoría para la manufacturación de ornamentos (Lucero et al. 2010); y profusos restos zooarqueológicos, con 21.496 fragmentos.

De este conjunto óseo, 3306 especímenes o mínimas unidades reconocibles fueron asignadas a elemento esqueletario, familia y taxa específica. Ellos son: llama (Lama glama) en ambas terrazas, interior mina y sector pasarela, con un $78,8 \%$ del NISP, recuperada en toda la secuencia ocupacional del sitio; cinco huesos de alpaca (Vicugna pacos); pescados como corvina (Cilus gilberty), pejeperro (Semicossyphus maculates), congrio (Genypterus sp.) y jurel (Trachurus symmetricus); aves en escasa frecuencia; chinchilla (probablemente Chinchilla lanigera), Phillotys sp. (aparentemente de depositación natural); Canidae; y en forma excepcional taruca (Hippocamelus antisensis) (Velásquez 2004). En relación con el recurso hídrico, los habitantes de la MLT contaban con dos discretas aguadas a menos de $10 \mathrm{~km}$ del sitio, una en el sector Pozo del Indio al norte y otra al sur en el Llano de San Juan.

La mayor ocupación se visualiza en la terraza 2, con el $49,3 \%$ de la muestra total de la cerámica del sitio $(\mathrm{N}=2796)$, mientras la terraza 1 solo evidenció un 7,4\% de la muestra cerámica, distribuyéndose el resto en otros espacios del sitio. No obstante, la cerámica da cuenta de una ocupación continua del yacimiento, desde el Período Formativo hasta épocas históricas (Uribe et al. 2004). En la terraza 1, asumiendo una importante disturbación de los depósitos, se distinguen dos concentraciones de materiales cerámicos, una en superficie y la otra entre los 30 y $87 \mathrm{~cm}$ de profundidad, con registro del Formativo, correspondientes a las primeras ocupaciones del sitio, las cuales son prontamente intervenidas por los grupos del Período Medio (Ánimas) y del Intermedio Tardío atacameño. Entre los 50 y $60 \mathrm{~cm}$ de profundidad se concentran los testimonios Tardíos e Históricos. Los materiales Ánimas se encuentran en toda la secuencia, aunque esto puede responder a la intervención de los grupos atacameños sobre un asentamiento preexistente (Uribe et al. 2004). 


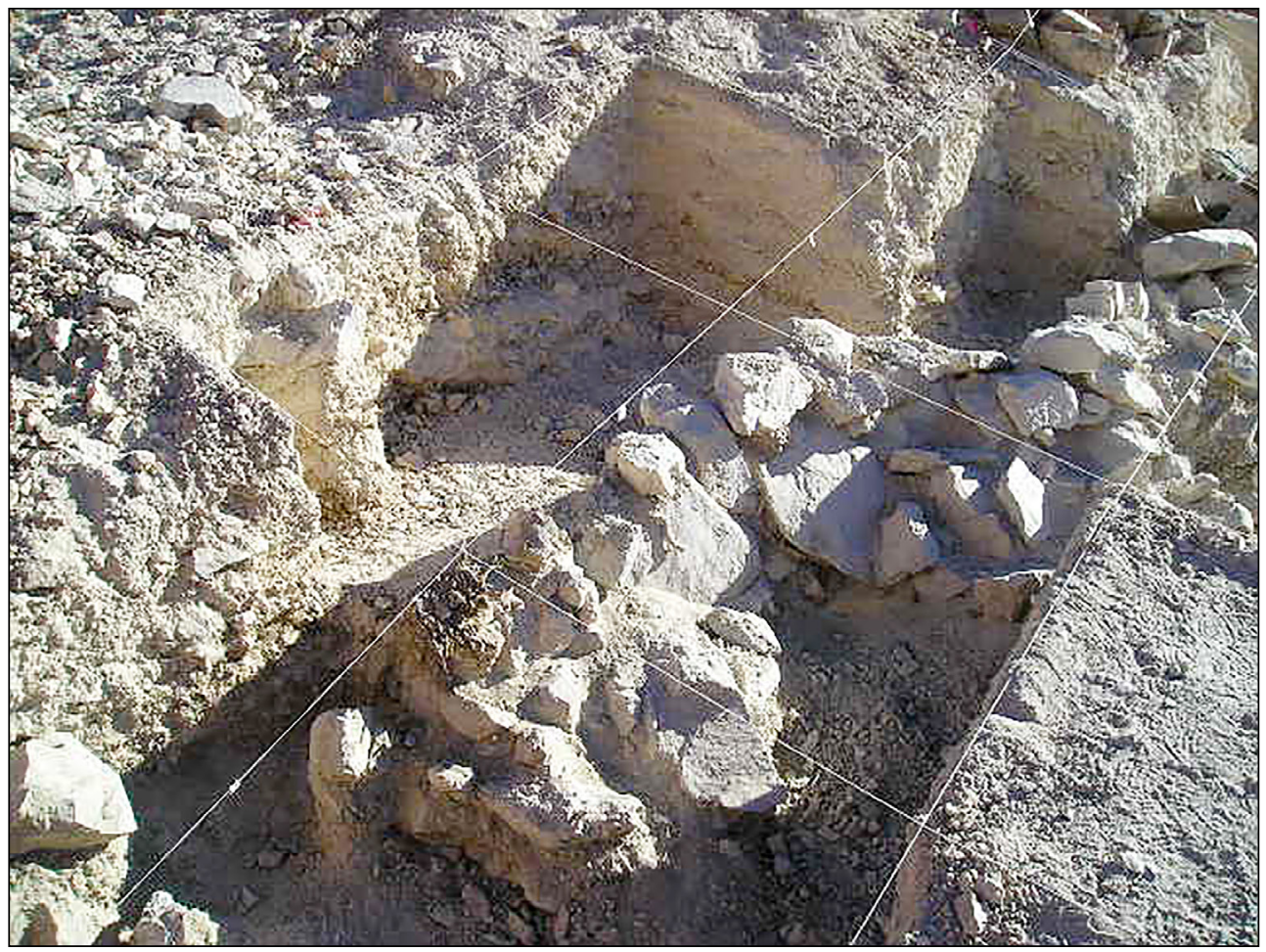

Figura 4. Despeje de muro (estructura 5) en terraza 1, durante el proceso de excavación.

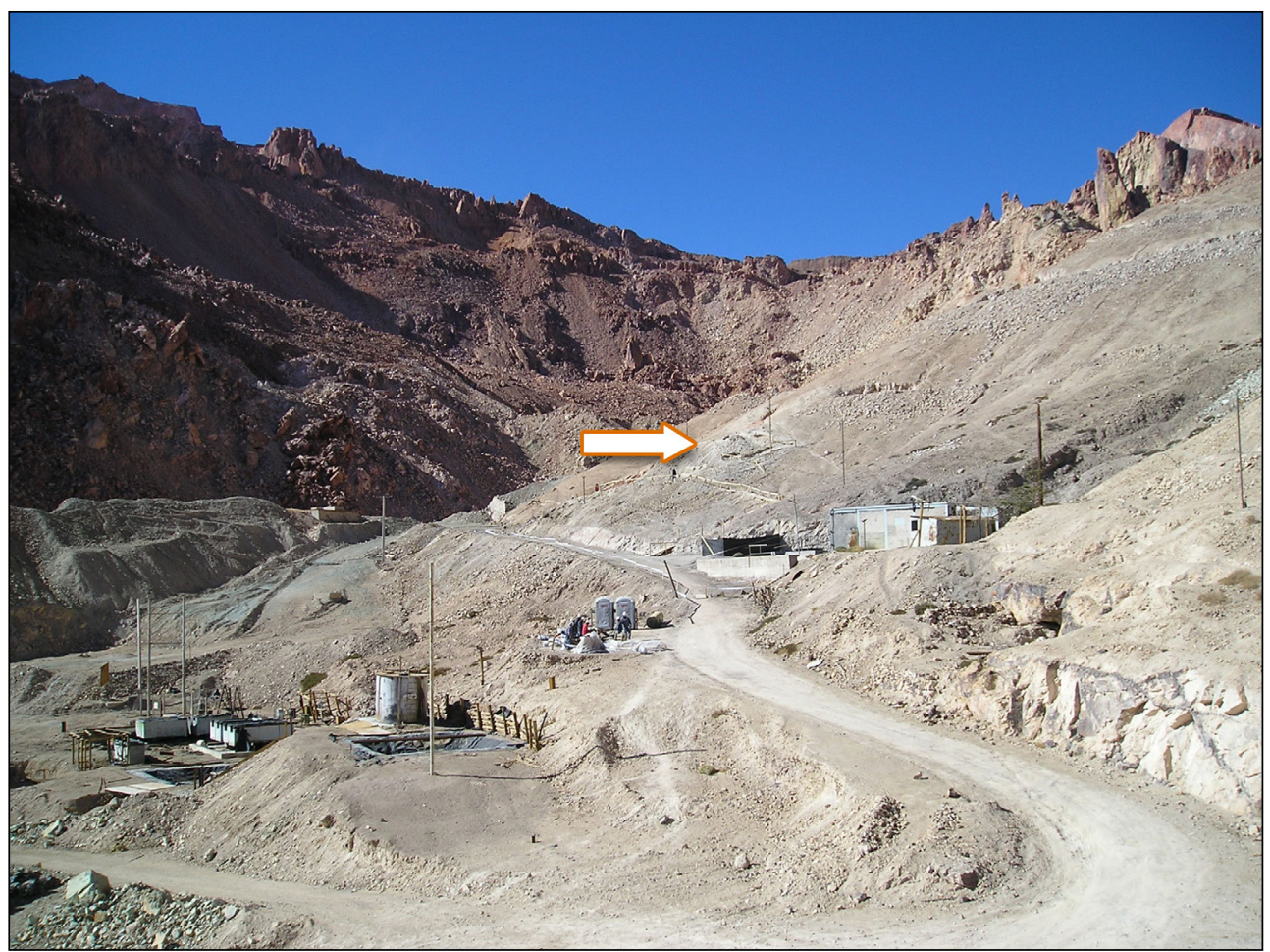

Figura 5. Camino secundario y MLT en el cerro Indio Muerto, indicada por la flecha (Fotografías Carlos González 2004). 


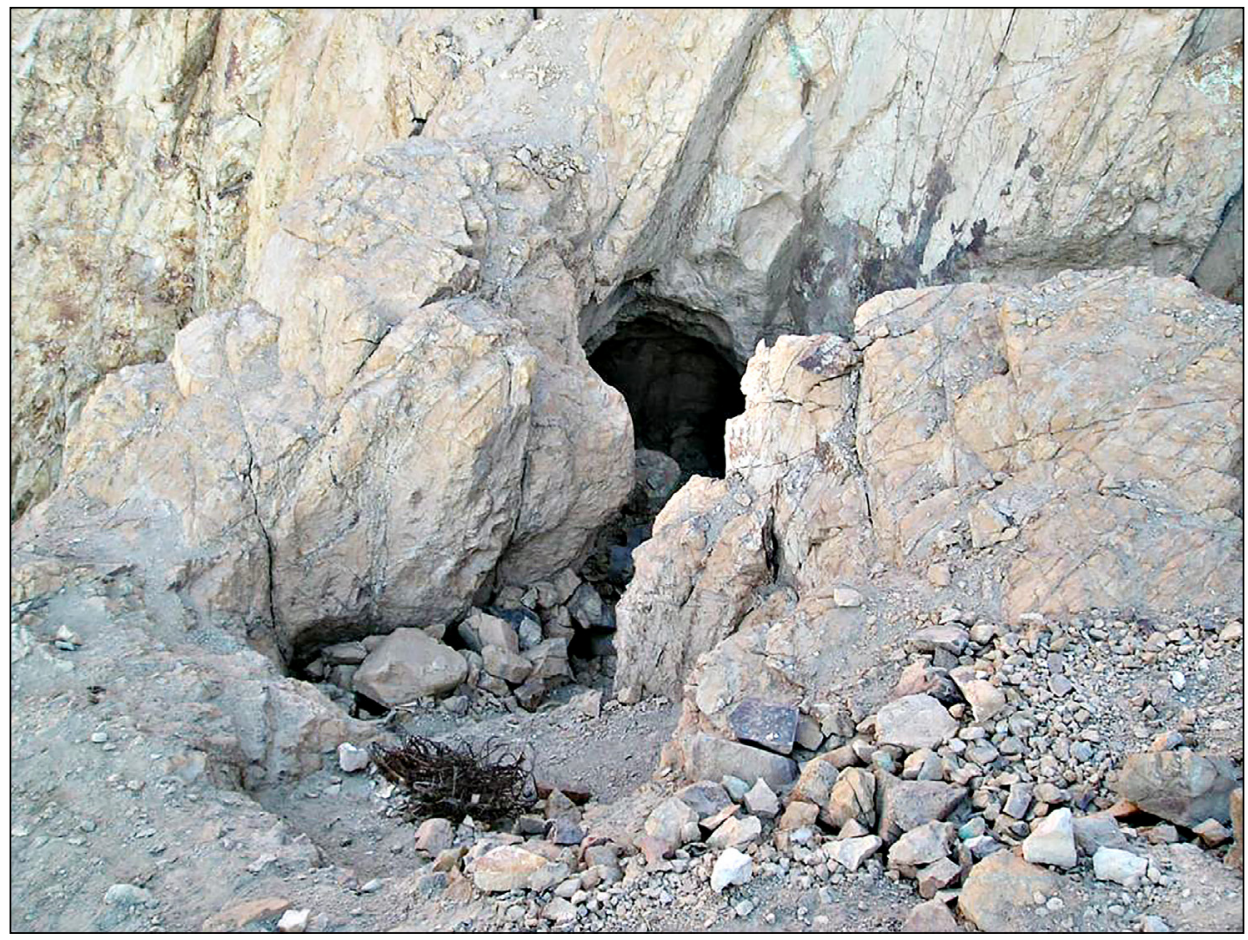

Figura 6. Entrada a la MLT (Fotografía Carlos González 2004).

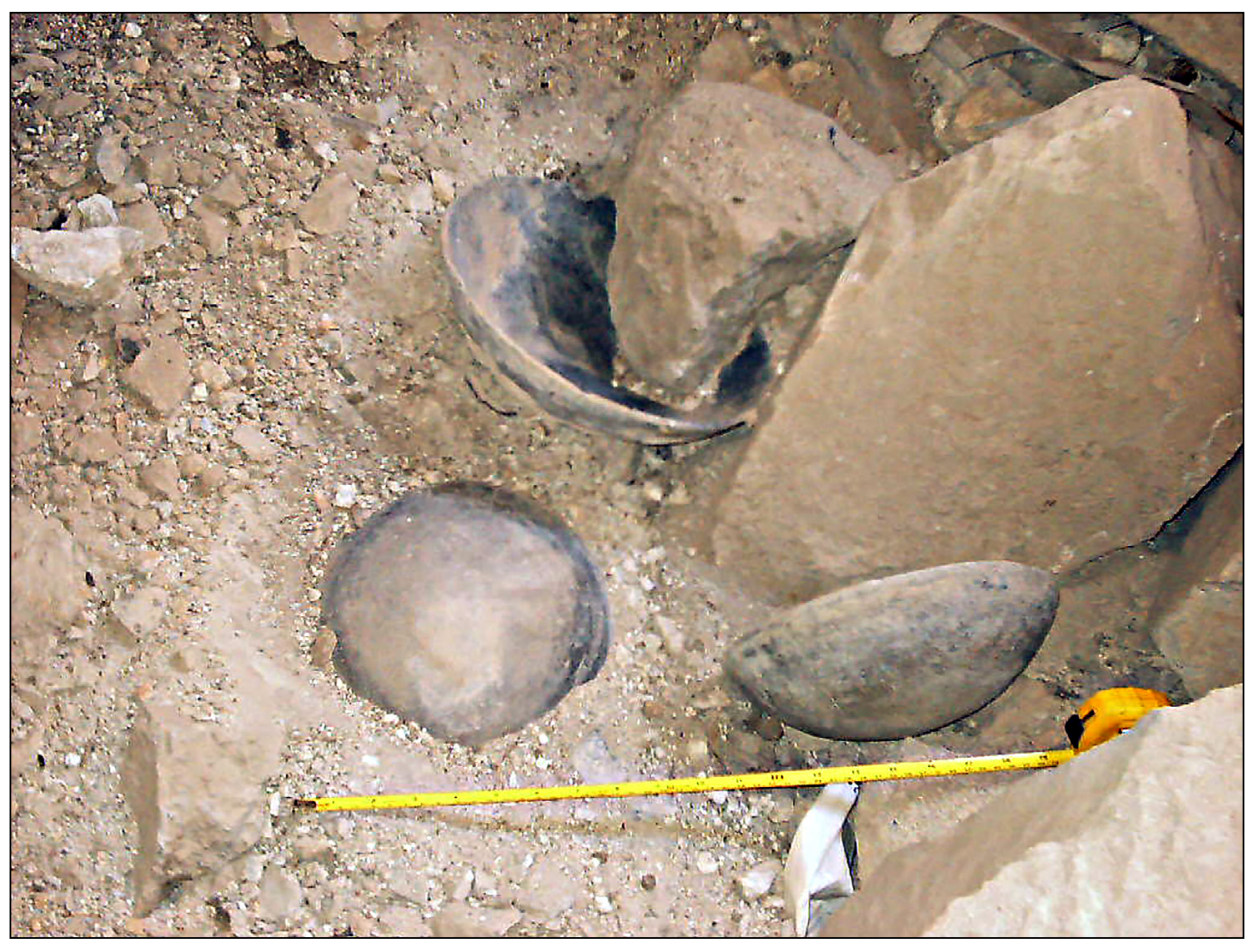

Figura 7. Despeje de los tres ceramios Dupont in situ, en derrumbe interior de la MLT (Fotografía Catherine Westfall 2004). 
En la terraza 2 no se reconoce un patrón específico de distribución espacial de los tipos cerámicos identificados, como consecuencia de reiteradas disturbaciones, al igual que en la terraza 1. La mayoría de los tipos aparecen hasta el metro de profundidad, presentándose los restos del Formativo en niveles superiores e inferiores de las excavaciones. Los referentes Tardíos e Históricos se encuentran en los niveles medios y no necesariamente en la superficie. También se aprecia una fuerte concentración de materiales en las unidades $\mathrm{Mo}, \mathrm{M}_{1}, \mathrm{M}_{2}, \mathrm{~K}_{3}, \mathrm{~K}_{7}$ y L4, con un momento temprano dentro del Intermedio Tardío, particularmente en los niveles inferiores de las unidades $\mathrm{M}$, donde se encontraría el núcleo de la ocupación atacameña en el sitio, el cual fue cortado por un camino subactual, como se mencionó antes. Nuevamente se visualiza la existencia de cerámica Ánimas a lo largo de la estratigrafía, con posibles remociones y eventuales episodios de contemporaneidad con las unidades sociales atacameñas, quienes luego copan todos los espacios del lugar (Uribe et al. 2004).

Ahora bien, los resultados de las excavaciones y el análisis cerámico determinan ocupaciones que se expresan por medio de una secuencia más horizontal que vertical (Uribe et al. 2004; Westfall y González 2010), asociadas a ocupaciones puntuales y recurrentes en el sitio y su entorno. Estas evidencias no apoyan la existencia de un núcleo poblacional de grandes dimensiones (Uribe et al. 2004), como una aldea o poblado. Por las disturbaciones de las ocupaciones sucesivas, es factible plantear la existencia de viviendas de material perecible, que pudieron apoyarse en bases aisladas de piedras, localizadas en algunos puntos del sitio, sin un orden definido.

Desde el punto de vista minero lapidario, se reconoce que la obtención de materias primas (turquesa, otros minerales y arcillas), la realización de tareas extractivas y las labores artesanales especializadas, se efectuaban en el mismo sitio (García-Albarido 2007). En este sentido, el análisis lítico indicó una producción fundamentalmente orientada hacia la elaboración de perforadores y microperforadores en rocas silíceas (Figura 8), principal actividad lítica en la MLT; la segunda es el trabajo de piezas pulimentadas, aparte de la confección de cuentas líticas finiquitadas (Figura 9), escasas en el sitio (Contreras 2004). El pulido de las cuentas tendría un referente por el hallazgo al interior de la mina de un trozo cilíndrico de madera confeccionado desde una rama o tronco descortezado. Esta pieza exhibe oquedades de distintos tamaños en sus extremos, algunas con adherencias de mineral, donde ubicarían las cuentas y eran pulidas (De Ugarte et al. 2010: 1216). Asociado a este objeto se obtuvo una piedra angosta y lisa de basalto, utilizada al parecer para pulir las cuentas; otra pieza similar fue ubicada en la terraza 1. Iribarren (1972-1973: 268) consigna cinco trozos cilíndricos de madera con oquedades, de "uso desconocido" del interior de la mina.

El quehacer minero es apoyado por labores domésticas (preparación y consumo de alimentos), como por actividades de almacenamiento y ceremoniales. Esto último lo confirma, por ejemplo, el tipo San Pedro Rojo Violáceo (SRV) del Intermedio Tardío atacameño (Uribe et al. 2004), recuperado en ambas terrazas, al interior de la mina y en el talud bajo un camino subactual. Además, se obtuvieron de las dos terrazas 25 fragmentos de espátulas de huesos, en su mayoría de porciones diafisitarias de un camélido grande (llama) (Velásquez 2004); instrumentos a lo mejor empleados para prácticas alucinógenas, sin descartar otros usos. Objetos similares son reportados en la MLT por Iribarren (1972-1973: 273-274). Cabe mencionar que tabletas de madera y una espátula de hueso -diferente a las recuperadas en la MLT- han sido registradas en el cercano Cementerio Las Turquesas (González y Westfall 2008). Posiblemente las espátulas de hueso estén presentes desde tiempos Ánimas en la MLT.

Por último, es importante consignar que próximo a la MLT se encuentra el Cementerio Las Turquesas. De este sitio se ha estudiado un individuo masculino, adulto, momificado naturalmente, el cual presenta ajuar y ofrendas, por el momento, asignables al Período Intermedio Tardío atacameño, ${ }^{10}$ demostrando igualmente actividades mineras y caravaneras relacionadas con la explotación de la próxima MLT (González y Westfall 2008), ubicada a más de $1 \mathrm{~km}$ al sureste.

Luego de exponer los aspectos esenciales sobre la caracterización arqueológica de la MLT, presentamos la periodificación prehistórica alfarera del sitio, a partir de sus elementos diagnósticos. Entendemos la MLT no solo

10 Están contemplados análisis de isótopos estables de este individuo, con la finalidad de discutir su procedencia. 


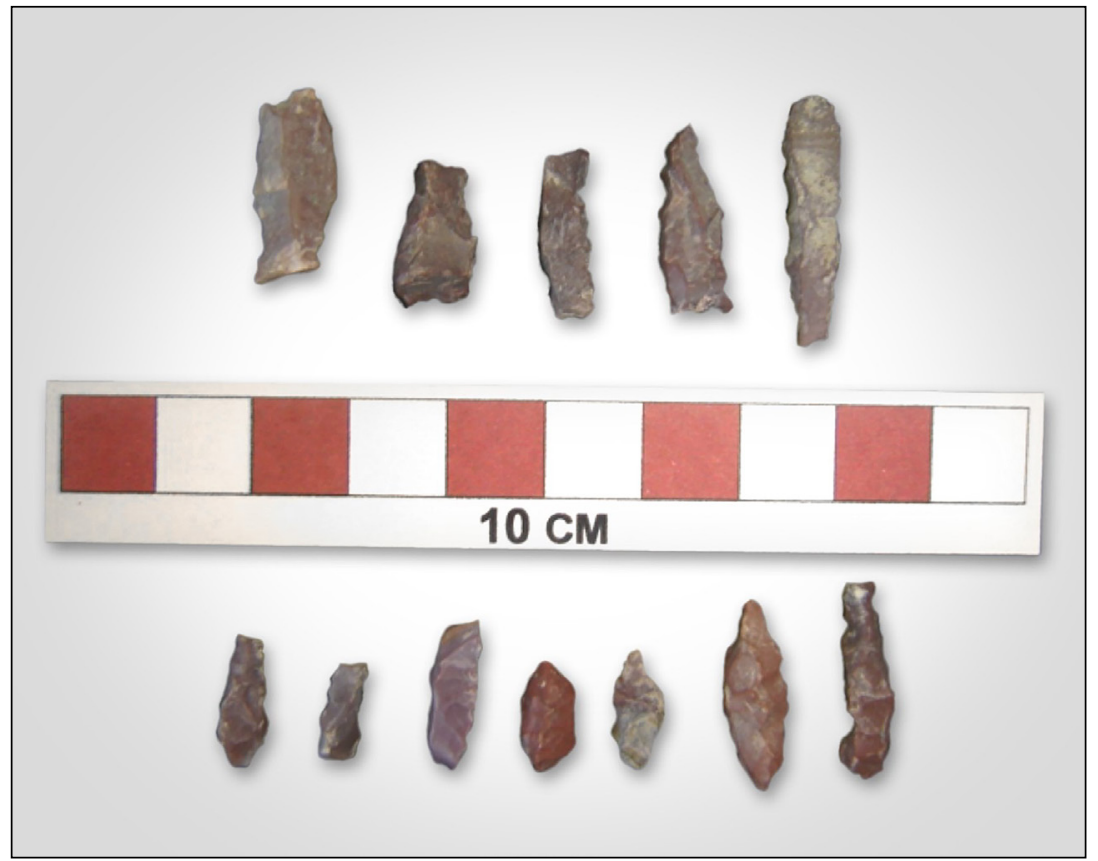

Figura 8. Preformas de perforadores, perforadores y microperforadores de la terraza 2, MLT (Fotografía Lino Contreras 2004).

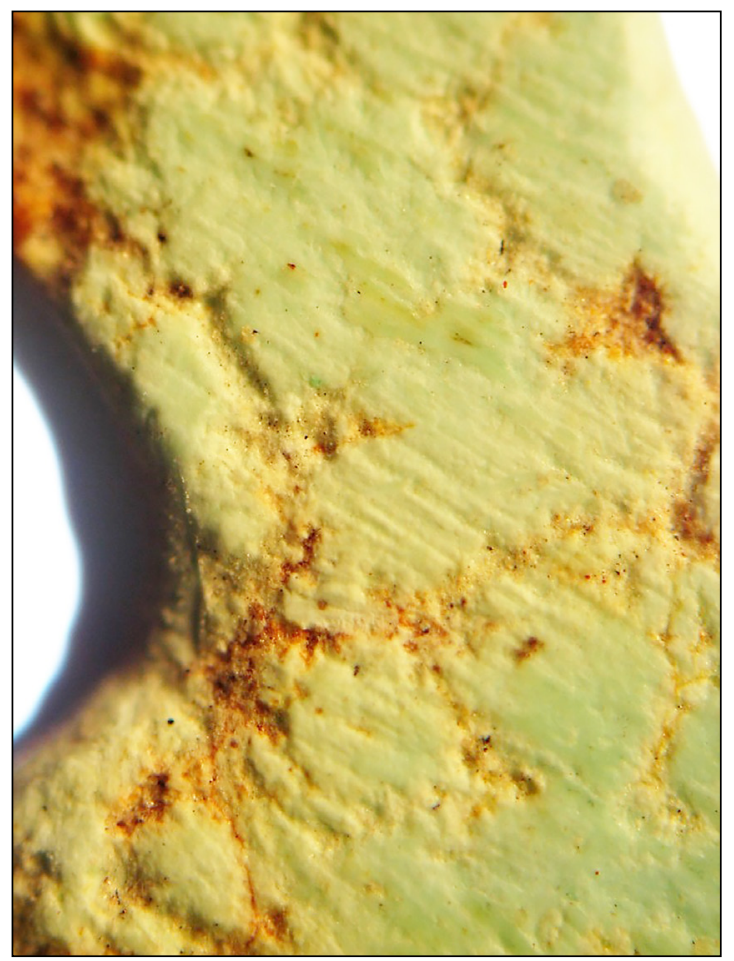

Figura 9. Cuenta de collar lítica con huellas de pulimento, sector de pasarelas MLT, recolección superficial (Fotografía microscópica Carmen Castells 2004). 
como un yacimiento minero extractivo, con una orientación netamente económica, que no negamos, sino también como un ejemplo de las probables interrelaciones culturales y de las variabilidades del desarrollo prehispánico en el territorio internodal de la comuna de Diego de Almagro. Valga señalar que hasta ahora están ausentes en nuestra área de trabajo grandes poblados, pukaras, asentamientos nucleados de gran envergadura o conglomerados estructurados. Esto responde a una de las particularidades de las áreas internodales, la baja demografía presente en un desierto absoluto (Nielsen 2006:35), y en los espacios inmediatos de la Puna Salada, que definen la geografía comunal y que generan restos arqueológicos de una singular naturaleza. De este modo, contamos en la comuna con ocupaciones alfareras distintivamente internodales, tanto de tránsito como extractivas (Nielsen 2006: 35), al igual que de otra clase, entre ellas espacios significados a través de un arte rupestre local, particularmente desde las épocas finales del desarrollo prehispánico (Finca de Chañaral, Aguada Los Guanacos, Aguada El Chinche, Alero de La Mano, Viña del Desierto, Tres Puntas 1 y 2, entre otros). Estos antecedentes posibilitan plantear determinadas dinámicas de ocupación del espacio, muchas de ellas a nivel de hipótesis interpretativas, que deben ser testeadas con futuras excavaciones en campamentos de tareas, enclaves productivos y otros, presentes en la comuna.

\section{Período Formativo (1200 AC - 600 DC, aprox.)}

A partir del Formativo atacameño podemos establecer los primeros registros de movimientos de las poblaciones del núcleo del oasis de San Pedro de Atacama y cuenca del río Loa hacia el sitio minero lapidario de la MLT, distante a más de $390 \mathrm{~km}$ en línea recta hacia el suroeste del centro de poder atacameño. En efecto, los datos del Formativo de la MLT están avalados por fragmentos cerámicos de los tipos Los Morros, Loa Café Alisado, Loa Rojo Alisado y San Pedro Negro Pulido (Uribe et al. 2004), abarcando desde aproximadamente el $500 \mathrm{AC}$ hasta el $600 \mathrm{DC}$, o tal vez mucho antes. No superan un $4,5 \%$ de la muestra total de cerámica del sitio, dando cuenta de dos acotados momentos, Temprano y Tardío dentro del Formativo (Uribe et al. 2004), lo que nos permite sugerir que la activación del sitio se debió a grupos formativos provenientes del nodo nortino atacameño. Están presentes particularmente en la terraza 2 y en el talud bajo el camino subactual.
En consecuencia, postulamos que dentro de los procesos culturales del Formativo comienza la explotación de la MLT, la que habría sido puntual, con eventos ocupacionales esporádicos, coincidiendo con que: "En esta época se inician las rutas de tráfico de traslado y colonización de recursos distantes" (Núñez 1991: 40), como la turquesa de la MLT. Además, se condice con otros contextos formativos de la circumpuna occidental, centrados en la elaboración de cuentas de collar líticas (Carrasco 2002; Rees 1999; Rees y De Souza, 2004; Soto 2010); sitios hasta aquí no conocidos en el norte semiárido y Chile central (Méndez com. pers. 2016; Pascual com. pers. 2016). Asimismo, desde el punto de vista tecnológico se constata a partir de este tiempo la utilización de los perforadores y microperforadores líticos en la MLT (Contreras 2004).

Hemos reconocido 24 fragmentos cerámicos de una pieza restringida Molle con "base en torus", obtenidos por Iribarren en 1969 del sitio, que se encuentran en el Museo Arqueológico de La Serena. Si bien anteriormente postulamos que este objeto podría testimoniar un evento u ocupación Molle en la MLT (González y Westfall 2005: 61), consideramos que su ínfima representación, junto con la ausencia de otros testimonios de la ergología Molle en las excavaciones de la MLT, como tembetás, pipas " $\mathrm{T}$ " invertida, fragmentación cerámica diagnóstica, entre otros, proponen su ingreso por otros mecanismos, quizás mediante intercambios y contactos, más que representar una ocupación. Esto no objeta la presencia Molle en la comuna, aunque pareciera manifestarse en baja frecuencia y acrecentar su número a partir del río Salado al sur. Así lo comprueban los restos Molle del sitio La Lasca, próximo a Inca de Oro, donde se recuperaron de dos tumbas señalizadas con bloques de piedras planas, varios ceramios, entre ellos uno negro pulido inciso, pipas y tembetás (Castillo y Kuzmanic 1981: 122-124). Se agrega cerámica gris-pulida-incisa y café alisada (vaso cilíndrico) en Finca de Chañaral, en una ocupación fechada en 340 DC (datación radiocarbónica convencional, no calibrada) (Cervellino y Sills 2001: 136). También se cuenta una pieza restringida Molle Rojo Grabado de Inca de Oro (Sinclaire com. pers. 2009).

Junto a estas evidencias, se conocen otros restos del Formativo Tardío atacameño en nuestra comuna. En el pequeño oasis de Quinta Los Chañares, inmediato a la ciudad de 


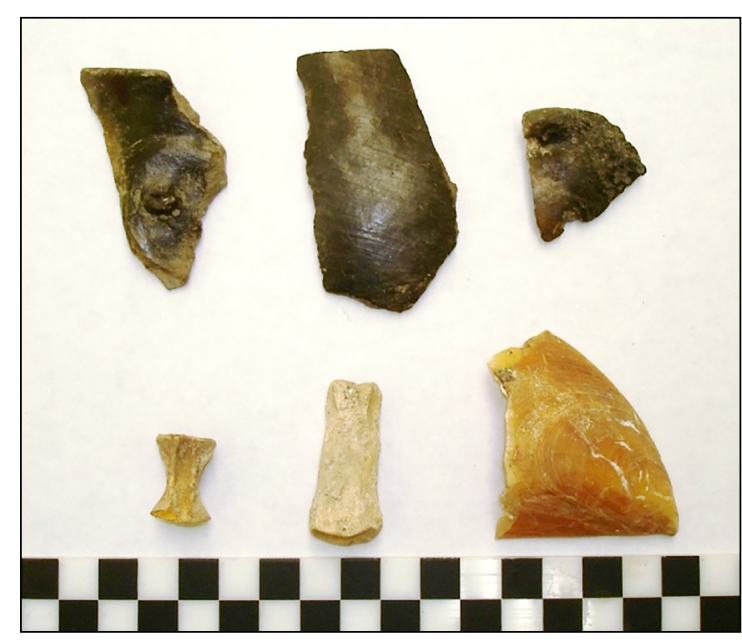

Figura 10. Sitio Quinta Los Chañares. Arriba, fragmentos cerámicos San Pedro Negro Pulido (Séquitor); abajo, restos zooarqueológicos y valva de almeja (Colección Museo Pueblo Hundido de Diego de Almagro).

Diego de Almagro y ubicado a más de $50 \mathrm{~km}$ al suroeste de El Salvador, fue recuperada en forma causal a fines de los noventa, de un contexto posiblemente habitacional, cerámica San Pedro Negro Pulido (SNP) en su variedad Séquitor, en mínima cuantía, asociada a otros productos trasladados (Figura 10). Igualmente, se cuenta con objetos cerámicos de esta filiación cultural en el sector de Inca de Oro, depositados actualmente en el Museo Chileno de Arte Precolombino (Sinclaire com. pers. 2009).

El ingreso de estas piezas obedecería a intercambios, y de la misma manera testifican la existencia de una ruta caravanera que conectaba el extremo meridional del desierto de Atacama con espacios circumpuneños occidentales nortinos, confirmando la circulación de objetos y el transporte de productos. De igual modo, la constatación de algunas evidencias viales en una ruta prehispánica paralela al Qhapaq Ñan, que vincularía los oasis de Quinta Los Chañares y Finca de Chañaral hacia el sureste, recientemente reconocida por nuestro equipo, ubicadas por un estudio de impacto ambiental en 2011 (Contreras com. pers. 2015), también cuentan con un posible antecedente Formativo. En un abra adyacente a esta ruta, hacia el sur del oasis de Quinta Los Chañares, se encontró fortuitamente en 1992 una lámina aurífera repujada y con orificio de suspensión, de forma subcuadrangular y con motivo de rostro antropomorfo radiado en relieve ${ }^{11}$

11 La lámina en vista frontal mide en su lado más largo $2,8 \mathrm{~cm}$ de

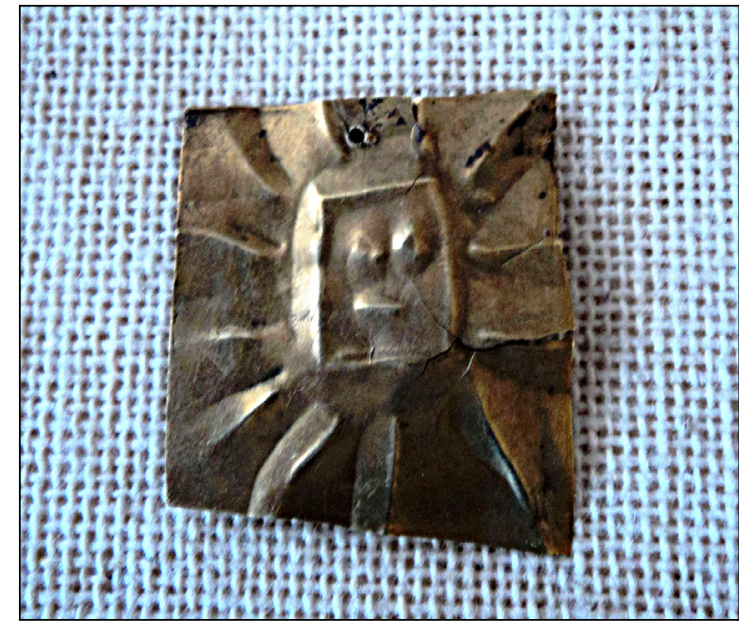

Figura 11. Lámina aurífera repujada con rostro antropomorfo radiado (colgante) (Fotografías Carlos González 2011).

(Figura 11). De acuerdo al informante estaba acompañada por un collar de cuentas cupríferas y otra lámina metálica oscura, iplata?, que se deshizo por completo.

Las especificaciones de esta pieza aurífera, el trabajo laminar, sus pequeñas dimensiones y el motivo del rostro humano radiado, la correlacionan con láminas similares encontradas en contextos formativos circumpuneños occidentales, algunas de ellas definidas como colgantes (Núñez 2006a: 244, com. pers. 2016; Westfall et al. 2010: 836-837). Presenta similitudes con una iconografía atacameña (Figueroa com. pers. 2016), y difiere notablemente de los objetos metálicos conocidos de El Molle (Niemeyer et al. 1989: 252-253), Ánimas (Castillo 1989: 270-271; Niemeyer 1998: 140), Copiapó (Castillo 1998; Gaete y Cervellino 2000: 618) y Diaguita (Latorre 2009), apoyando su posible adscripción formativa circumpuneña.

Pese a los referentes formativos de la MLT, consideramos que no es posible ampliar esta determinación cultural al resto de la comuna, ya que de momento no están presentes en este espacio internodal definiciones culturales generales del Formativo, entendido como "el proceso de transformación de las sociedades hacia la vida aldeana bien establecida, a través de las implicancias revolucio-

alto y en su lado más corto $2,5 \mathrm{~cm}$, con un ancho máximo de 2,4 $\mathrm{cm}$ y un espesor de $0,01 \mathrm{~cm}$. 
narias que se generaron en el tránsito a la producción de alimentos" (Tarragó 2002: 303). Tampoco hemos hallado sitios que aporten al reconocimiento de cambios socioculturales, que impliquen la instauración de una vida aldeana de sociedades agropastoriles, probablemente jerarquizadas (Núñez 2006b). Además, la circulación de objetos del Formativo circumpuneño no constituye un argumento para definir la existencia de este período cultural en el territorio que nos preocupa.

\section{Período Medio (600 - 1000 DC, aprox.)}

En relación con los componentes culturales de este tiempo, encontramos un cambio del núcleo ocupacional preeminente en la MLT. En efecto, el trabajo minero lapidario pasa a manos de los grupos Ánimas, quienes implementan una ocupación preferente en el sitio, con mayor incidencia en la terraza 2, siendo ínfimo el registro atacameño, el cual se remite a cerámica San Pedro Negro Pulido Quitor ( $\mathrm{NP}_{2}$ ) y San Pedro Negro Pulido Inciso Coyo (COY) (0,14\% de la muestra total) (Uribe et al. 2004) (Figura 12). Los testimonios atacameños toman mayor fuerza desde fines del Formativo y se expresan luego en escasos restos alfareros del Período Medio del Salar de Atacama (400-950 DC), presentes en ambas terrazas y al interior de la mina (Uribe et al. 2004). Desde esta perspectiva, es posible plantear que el conocimiento de la MLT por parte de los grupos Ánimas, haya sido producto de los contactos con las comunidades atacameñas formativas, las cuales iniciaron su explotación.

La exigua cuantía de cerámica del Período Medio atacameño, nos lleva a proponer intercambios entre los grupos Ánimas, asentados en la MLT y que provendrían de Finca de Chañaral y del valle de Copiapó, con las comunidades atacameñas de los nodos nortinos. Las características de la ocupación Ánimas, posiblemente expresada en un asentamiento, exhibe una mayor permanencia o recurrencia en el sitio, con una acentuada utilización de ollas para la preparación de alimentos (Uribe et al. 2004), unidas a minoritarios ejemplares alfareros no restringidos Ánimas II y negro pulido (Figura 13); cerámica negra pulida no restringida, pero con decoración incisa, fue recuperada del Cementerio La Puerta A (Niemeyer 1998: 144, 146-147). Incluso, los grupos Ánimas de la MLT llegan a construir un depósito de piedras en el sitio (cuadrícula L7, terraza 2), del cual se fechó una muestra de carbón por medio de una precisión radiocarbónica convencional

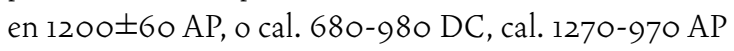
(Beta-196861, Carbón) (González y Westfall 2005: 60).

Se unen a este fechado dos dataciones por termoluminiscencia de la MLT obtenidas por nuestro equipo. Una de ellas corresponde a un fragmento Ánimas II de una pieza no restringida, negro pulido interior y pulido exterior, con decoración lineal negro sobre color natural (cuadrícula Mo, nivel 12), que arrojó $1150 \pm 70$ DC (UCTL 1714). La otra, de un fragmento cerámico de una pieza restringida Ánimas, negro pulido exterior y café alisado interior (cuadrícula $C_{9}$, recolección superficial), entregó $1190 \pm 80$ DC (UCTL 1720). Estas fechas son coherentes con dataciones obtenidas para sitios Ánimas del valle de Copiapó (Niemeyer 1998: 154; Troncoso y Pavlovic 2013: 126), dando cuenta de un desarrollo contemporáneo con la MLT. Por lo tanto, y unida a la precisión radiocarbónica del depósito, definen una ocupación Ánimas en la MLT, con episodios probablemente relacionados con el Período Medio del valle de Copiapó.

Los componentes Ánimas corresponden a la segunda ocupación más significativa de la MLT. En términos de evidencias cerámicas comprende un 33,6\% de la muestra total (Uribe et al. 2004). Uno de los intereses de los grupos Ánimas, que los habría impulsado a desplazarse desde el nodo del valle de Copiapó hasta el sitio MLT, sería la obtención de turquesas, minerales y otras materias primas pétreas para confeccionar sus abalorios, fundamentalmente cuentas de collar y litoesculturas zoomorfas en miniatura. Estas últimas se han registrado en el Cementerio Ánimas de La Puerta A, en el valle de Copiapó (Niemeyer et al. 1995: 188), al igual que en la MLT (González y Westfall 2005: 54), mostrando en este último sitio distintas etapas del proceso de elaboración de diversas figurillas (Contreras 2004). Al menos en La Puerta A, estos productos son incorporados a los contextos funerarios Ánimas (Niemeyer 1998).

Destacable es que esté presente solo la llama (Lama gla$m a)$ en toda la secuencia ocupacional del sitio, con un $78,8 \%$ de la muestra total zooarqueológica identificada de 3306 fragmentos óseos, demostrando el manejo de camélidos domesticados, aptos para las labores caravaneras, que implican el transporte de bienes y productos a largas distancias. El análisis zooarqueológico indicó la 


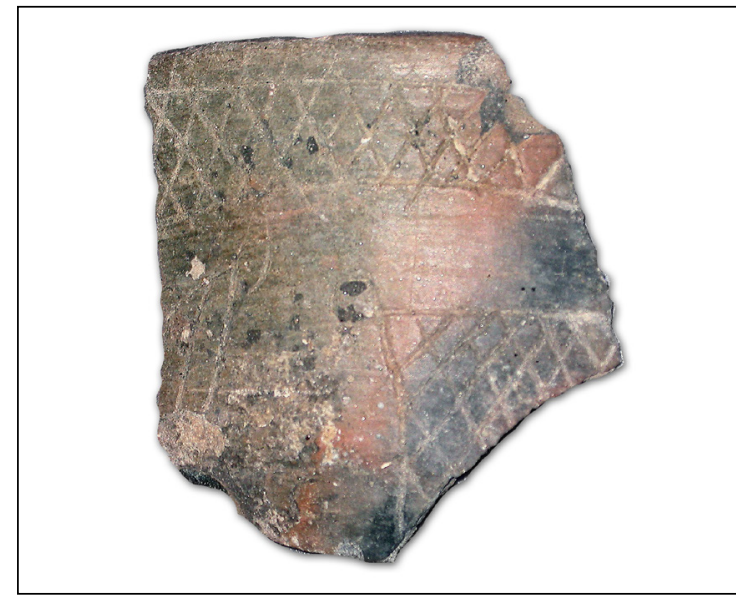

Figura 12. Fragmento cerámico San Pedro Negro Pulido Inciso Coyo de la MLT (cuadrícula K5, nivel 8).

existencia de individuos neonatos, juveniles y adultos, con una disposición permanente del recurso, sin considerar decisiones de costo de transporte, lo que indicaría posiblemente el uso de corrales en el sitio (Velásquez 2004), no detectados por nuestros trabajos. Por tanto, podemos sugerir que la ocupación Ánimas de la MLT contó con el recurso llama, y es factible proponer que lo utilizaran para emprender movimientos longitudinales, entre el enclave minero lapidario de la MLT, Finca de Chañaral y el nodo del valle de Copiapó; aunque por ahora esto no pasa de ser una conjetura, porque también pudieron adquirir el recurso por intercambios. Este problema adolece en el presente de mayor investigación en la región de Atacama.

Por su parte, en el camino inca que se proyecta por el cerro Indio Muerto, implementado sobre una ruta preincaica, se recolectó fragmentación cerámica Ánimas I de dos piezas no restringidas, en las cercanías del sitio Sal 4 (González et al. 2010: 74, 86), correspondientes al parecer a evidencias de desplazamientos hacia o desde la MLT. Mientras que Cervellino y Sills (2001: 136), en un sendero ubicado en el oasis de Finca de Chañaral, registran cerámica Ánimas I y en otro sector fragmentos café y gris, con la misma asignación cultural. Igualmente, mencionan que en 1986 y 1987 efectuaron excavaciones en cuatro túmulos (con un enturbantado) y basurales de este oasis. Seguel (1986a, 1986b), quien participó en una primera etapa, refiere excavaciones en tres túmulos con mínimos resultados.

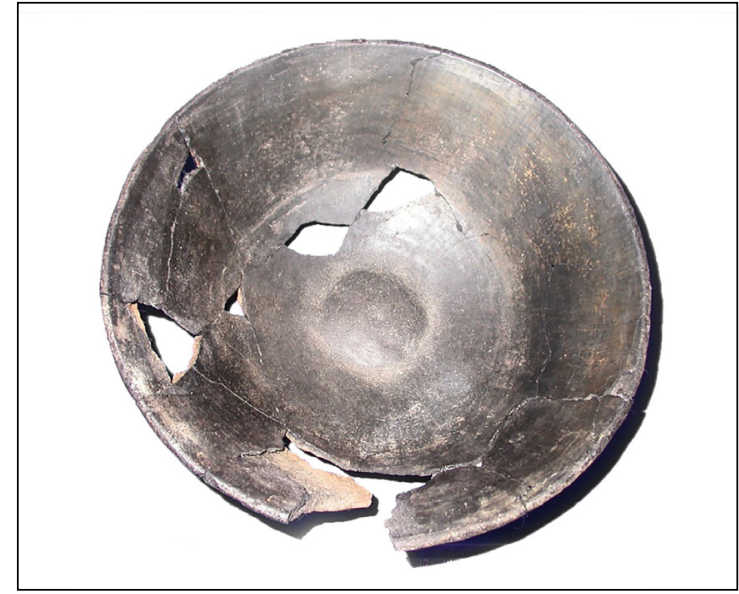

Figura 13. Ceramio Ánimas negro pulido (pasarela terraza 1, MLT) (Fotografías Mauricio Uribe 2004).

Durán (2008) reporta excavaciones en dos túmulos en 1987, recuperando en uno de ellos a un individuo con un gorro de lana (rojo, azul y café, con algunas manchas moradas) - ¿el enturbantado de Cervellino y Sills?-, trozos de cestería, fragmentos de tejidos, cerámica, carbón, líticos, icoprolitos?, entre otros; también informa una recolección superficial en el sector de los túmulos. Estos antecedentes dan cuenta de un paisaje significativo, por los túmulos funerarios ubicados en la salida sur del oasis de Finca de Chañaral, que por tradición se inscriben a los desarrollos Ánimas, pese a que esta filiación no se encuentra confirmada plenamente. Por último, Cervellino y Sills (2001: 136) mencionan fragmentos cerámicos Ánimas en la superficie del tramo del camino inca entre las localidades de Inca de Oro y el norte de El Salvador. En consecuencia, y tomando en cuenta estos datos, sostenemos que la ruta incaica tiene un precedente en Ánimas, tal como lo habían señalado anteriormente los últimos autores. Sin embargo, los restos arqueológicos de la MLT sustentan ocupaciones formativas del núcleo atacameño, que seguramente conectaron los espacios circumpuneños, activando, junto a otros grupos culturales, la ruta que atravesaba el Despoblado de Atacama hasta Copiapó.

De esta manera, se constatan hasta el momento en varios puntos del territorio comunal los tipos Ánimas I y II -junto a otras formas restringidas y el tipo negro pulido en la MLT (Uribe et al. 2004)-, coincidente con la situación del valle de Copiapó, donde predominan estos mismos tipos cerámicos (Troncoso y Pavlovic 2013: 
112-113). Por consiguiente, estimamos que una ruta importante en este tiempo es la que conecta el valle de Copiapó con Finca de Chañaral y llega al cerro Indio Muerto en El Salvador. No contamos hasta el momento con evidencias materiales de vialidad Ánimas, ya que esta ruta presenta variados restos arqueológicos viales. De allí que la inferencia de los movimientos Ánimas surge como hipótesis interpretativa desde la ocupación de la MLT, su asociación con el recurso camélido (llama) y su registro en algunos puntos de la comuna de Diego de Almagro. Esto no significa extender un manejo caravanero Ánimas con llamas para toda la región de Atacama, sino más bien postular vinculaciones entre el valle de Copiapó y el espacio de la comuna en cuestión. Según nosotros, este proceso se habría visto fortalecido por las continuas interrelaciones culturales entre las poblaciones Ánimas y circumpuneñas, además de los posibles contactos con comunidades trasandinas.

No queda claro el abandono Ánimas de la MLT, pero descartamos que sea producto de un reemplazo mecánico. Posiblemente se haya generado por un sistema social que no mantuvo un flujo constante para el mantenimiento de las familias en el sitio, el cual necesariamente requería de abastecimientos continuos. Asimismo, no consideramos que la ocupación Ánimas de la MLT pueda ser definida como una "colonia", tradicionalmente conceptualizada dentro de una orgánica política y socioeconómica más regulada. Por lo contrario, creemos que respondería al accionar de determinadas comunidades del nodo copiapino, para quienes la turquesa y otros minerales habrían tenido una connotación más simbólica y social, que política y económica. Tampoco apreciamos una continuidad en la MLT de los grupos Ánimas con las comunidades de la cultura Copiapó, las que no acceden a este foco minero lapidario.

\section{Período Intermedio Tardío (100o - 1400 DC, aprox.)}

Junto a la ocupación de la MLT y el Cementerio Las Turquesas (en adelante CLT), se cuenta con otros registros de este tiempo en la comuna de Diego de Almagro, con disímil adscripción cultural. Estos últimos se encuentran, por el momento, en el oasis de Finca de Chañaral y en sitios cercanos al pueblo de Inca de Oro. En la MLT se observa una situación singular, pues las evidencias del período dicen relación únicamente con manifestaciones culturales atacameñas..$^{12}$ Estos testimonios plantean la probabilidad de la habilitación de un enclave de mineroscaravaneros y artesanos especialistas en el trabajo minero lapidario (García-Albarido 2007; González y Westfall 2008). Desde el sitio se habrían proveído de cuentas de turquesa y de otros minerales, más distintos adornos, tal vez como bienes de estatus (Nielsen 2007), a los núcleos poblacionales del oasis de San Pedro de Atacama y cuenca del río Loa, inversamente a los primeros registros atacameños formativos del sitio, con episodios esporádicos. Este comportamiento, probablemente, habría favorecido en un comienzo un desplazamiento de los precedentes grupos Ánimas, mediante una ocupación quizás rápida de todos los rincones del sitio, por parte de las agrupaciones familiares de raigambre atacameña, al menos desde el 900 DC. Al mismo tiempo, aludiría a episodios de coexistencia entre estas comunidades.

La presencia atacameña se confirma en el sitio con los tipos cerámicos Dupont (DUP), Aiquina (AIQ), Turi Gris Alisado (TGA), San Pedro Rojo Violáceo (SRV), Turi Rojo Revestido Alisado (TRR), Turi Rojo Revestido Pulido (TRP), Turi Rojo Alisado (TRA) y Turi Rojo Burdo (TRB) (Uribe et al. 2004). En su conjunto representan ocupaciones acordes con la fase cultural Yaye-Solor, alrededor del 900 DC, y las subsiguientes fases del desarrollo tardío atacameño (Uribe 2002; Uribe y Adán 2005). Los indicadores cerámicos del Intermedio Tardío comprenden un $46,5 \%$ de los fragmentos obtenidos, representando la ocupación más significativa del sitio. Las redes caravaneras en este tiempo incluyeron al enclave atacameño de la MLT, integrando este espacio minero y artesanal en las dinámicas culturales circumpuneñas (Castro et al. 2016: 277; Salazar et al. 2013: 86-87).

Este período fue fechado por ${ }^{14} \mathrm{C}$ convencional con una determinación de $530 \pm 50$ AP, o cal. DC 1310-1370, cal. 640-580 AP (Beta-196246, Carbón), obtenida de un fogón en cubeta de la terraza 1 (rasgo 1, cuadrículas B3-B4, o,6o m de profundidad) (González y Westfall 2005: 60), asociado a la cancha de chancado implemen-

12 El análisis cerámico de la MLT indicó tres dudosos fragmentos Copiapó (Uribe et al. 2004). Uno se ubicó próximo al camino inca (empalme) y otros dos en el talud bajo un camino secundario, fuera del centro del sitio (terrazas e interior mina). De ser efectiva esta asignación, consideramos que estarían vinculados con el accionar Tardío del sector. 
tada en este tiempo. Complementa estos datos cerámica Aiquina (Sal-4) en el tramo de camino inca del cerro Indio Muerto. No obstante, podría corresponder a un testimonio posterior, dado que esta cerámica sigue produciéndose en tiempos incaicos en el núcleo atacameño (Berenguer et al. 1986: 48). Estos referentes se unen al ajuar y ofrendas del individuo masculino adulto del CLT, que fue adscrito al Período Intermedio Tardío (González y Westfall 2008), a lo mejor del ámbito circumpuneño occidental, como se indicó antes. De las excavaciones que efectuamos en 2009 en el CLT, pudimos comprobar la habilitación de 12 fosas mortuorias (vacías), localizar tres restos óseos humanos (fragmento distal de tibia derecha, vértebra toráxica y porción distal de un fémur derecho) y un fragmento de una aguja de cactus (González et al. 2009). La existencia de otro cuerpo momificado del CLT (Andino 1957: 2), correspondiente a un individuo femenino adulto, hoy en el Museo Regional de Atacama, sugiere la instalación de grupos familiares en el enclave minero lapidario, tal como lo manifiesta el análisis cerámico de la MLT, que enfatiza la preparación y el consumo de alimentos en el sitio, debido al predominio de platos Aiquina y Dupont (Uribe et al. 2004) (Figura 14).

La existencia de alimentos y variados productos alóptonos en la MLT, al igual que algunos elementos del individuo del CLT (González y Westfall 2008), grafican el traslado de objetos y productos hacia el enclave de la MLT, cuyo mecanismo implementado es la articulación de las redes caravaneras circumpuneñas. En vista de lo anterior, constituye un sitio que fue abastecido de alimentos, productos e insumos varios en forma permanente durante el Intermedio Tardío atacameño. Como ya lo hemos detallado, apoyan un determinado trabajo minero extractivo en el sitio MLT y un quehacer artesanal especializado. La orientación caravanera obedece primeramente a un pastoralismo eficiente y a un acendrado conocimiento de las rutas camineras del Despoblado de Atacama, las cuales eran recorridas en épocas previas, según los registros formativos de la MLT y de otros reconocidos en la posterior ruta inca (Niemeyer y Rivera 1983: 155). La llegada de las agrupaciones familiares de mineros-caravaneros y artesanos atacameños desde el norte durante el Intermedio Tardío, se habría gestado desde los núcleos de poder político de las comunidades asentadas en los poblados, que ocuparon durante este tiempo las quebradas del Loa y San Pedro de Atacama (Uribe 2012: 94, 99).
Mientras se genera esta situación en la MLT, en el caso de los antecedentes del Intermedio Tardío del oasis de Finca de Chañaral, se refieren a grupos portadores de cerámica Copiapó (González 2008; Iribarren y Bergholz 1972-1973: 253) (Figura 15) y Punta Brava (Cervellino y Sills 2001: 136); aunque por ahora se desconocen las características específicas del período en esta localidad. Un fechado por termoluminiscencia de un fragmento Copiapó de este oasis, obtenido de una excavación del equipo de la Universidad de Chile (Proyecto Qhapaq Ñan-CMN, 2010) en el sector central del oasis, sección este (unidad 3, nivel III), determinó $950 \pm_{100}$ DC (UCTL 2065). Esta datación da cuenta de grupos con cerámica Copiapó desde los inicios del período en el oasis, de otras comunidades de fines del Período Medio que transportaban esta clase de objeto, o de una pieza que circulaba bajo otras pautas culturales. Sea cualquier alternativa, esta fecha es contemporánea con los primeros componentes Intermedio Tardío atacameños de la MLT.

Del mismo modo, hemos localizado algunos sitios con portadores de cerámica Copiapó en los alrededores de Inca de Oro, a más de $60 \mathrm{~km}$ al suroeste de El Salvador, sumándose cerámica Punta Brava en uno de ellos (Aguada El Chinche). Corresponden a probables asentamientos en aguadas significados con arte rupestre (pinturas); acaso realizado desde este tiempo en adelante. La existencia de estos grupos no se condice con la ausencia momentánea de elementos de esta cultura en sitios de la precordillera y puna de la comuna de Diego de Almagro (González y Castells 2010). Situación diferencial a la presente en el valle de Copiapó y curso superior, nodo de esta cultura (Garrido 2007), donde sí se han consignado sitios con componentes culturales Copiapó preincaicos y de tiempos tardíos (Castillo 1998; Cervellino y Gaete 2000). Iribarren (1972-1973: 277, 279) menciona cinco fragmentos cerámicos Copiapó Negro sobre Rojo del interior de la MLT. Por el dibujo y la descripción del autor, son trozos de piezas incaicas (tres exhiben decoración fitomorfa) y no Copiapó.

Como hipótesis de trabajo postulamos que estas distinciones obedecerían a la sobresaliente ocupación atacameña preincaica hacia el norte de la comuna, como acontece en el sector del cerro Indio Muerto, implementándose una espacialidad atacameña vinculada a las redes caravaneras del Intermedio Tardío circumpuneño, que utilizan 


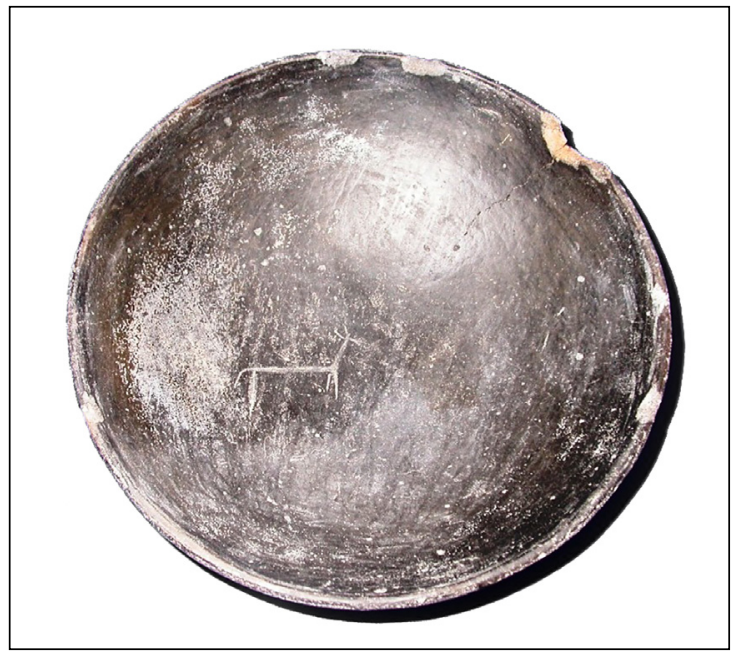

Figura 14. Cerámica Dupont con grabado de camélido, interior mina, MLT (Fotografía Mauricio Uribe 2004).

la ruta longitudinal que se proyecta por el Despoblado de Atacama, hasta llegar a El Salvador. Situación que difiere del comportamiento de las comunidades portadoras de cerámica Copiapó, presentes en algunas aguadas y bolsones fértiles, como también en campamentos de tareas de la comuna, en espacios previos a la Quebrada del Salado. Posiblemente estos grupos no incursionaron hacia el norte de este punto, que habría estado bajo el control sociopolítico de los atacameños, expresando, quizás, diferenciales nociones de territorialidad, sin que esto niegue los intercambios, los contactos y la circulación de productos y objetos, en el marco de fronteras culturales flexibles.

Escasos fragmentos Copiapó, junto a cerámica inca, se han detectado en el sector norte de la ruta incaica del Despoblado de Atacama, concretamente en la superficie del "Tambo" de Barrancas Blancas, considerados como testimonios de movimientos anteriores al Inka (Niemeyer y Rivera 1983: 123, 155, 176). Sin embargo, parecen representar trozos de un objeto que circula por la ruta, junto a otras piezas, en tiempos tardíos. Este caso puntual visibiliza el problema que también presentan algunos sitios con cerámica Copiapó en el valle homónimo, ya sea para adscribirlos al Intermedio Tardío o a tiempos incaicos (Troncoso et al. 2016:351), puesto que la cerámica Copiapó Negro sobre Rojo forma parte tanto de contextos incas como previos (Castillo 1998).

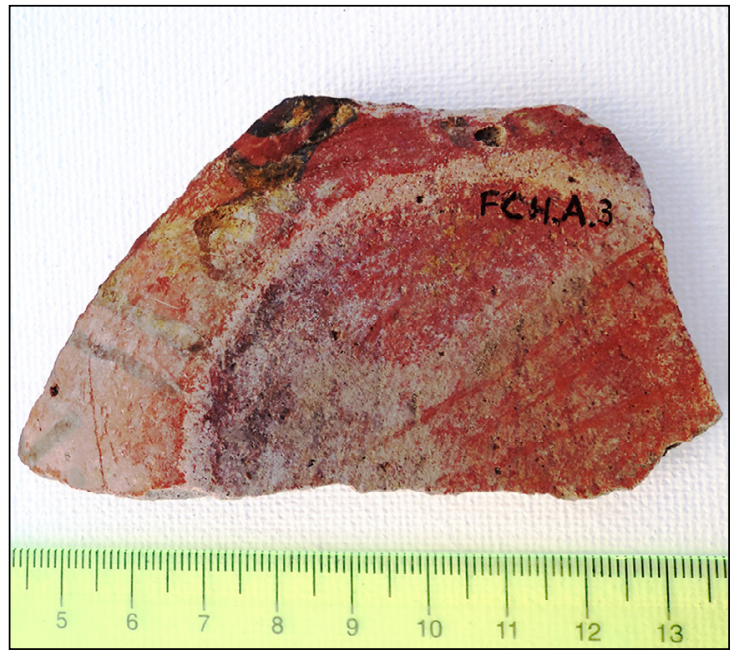

Figura 15. Fragmento Copiapó Negro sobre Rojo (base), con pigmento rojo adherido, Finca de Chañaral (Fotografía Carlos González 2016).

Los desplazamientos de los grupos portadores de cerámica Copiapó al sur del Salado, apuntarían preferentemente a la obtención de recursos mineros, entre ellos pigmentos, empleados estos últimos en la elaboración de un arte rupestre local, con el predominio de figuras antropomorfas y de camélidos (sitios en los alrededores de Inca de Oro: Viña del Desierto, Alero de La Mano, Aguada El Chinche, entre otros). No obstante, mientras estos sitios carezcan de fechados, incluso contando algunos con cerámica Copiapó Negro sobre Rojo, su asignación al Intermedio Tardío no es definitiva, ya que pueden corresponder a manifestaciones culturales de época incaica o a conductas particulares dentro del Tardío.

\section{Período Tardío (alrededor 1400 - 1536 DC)}

En la MLT se determinó que en este tiempo la ocupación de la mina sigue bajo el control de los grupos atacameños, quienes integran cerámica Turi Rojo Revestido Pulido Ambas Caras (TPA) y Turi Rojo Revestido Exterior-Negro Alisado Interior (TRN), que se definen como inca local (Uribe 1999) del ámbito circumpuneño occidental. En baja frecuencia en el sitio (0,8\%, Uribe et al. 2004) se recuperaron en las terrazas 1 y 2 , al interior de la mina y en un talud bajo un camino subactual. Una datación por termoluminiscencia de un fragmento del tipo TRN de la MLT (Uribe et al. 2004) (cuadrícula Eı1, nivel 6) obtenida por nuestro equipo entregó $1305 \pm 60$ DC (UCTL 
1716). Pese a que la fecha determina una precisión cronológica dentro del Intermedio Tardío, estimamos que debe ser entendida con la aplicación del sigma positivo, ubicándola hacia el final de este período y comienzos del Tardío. Este fechado, con la adición antedicha, es coherente con dataciones tempranas incaicas en el territorio circumpuneño nortino occidental (Cornejo 2014).

A estos tipos inca local circumpuneños se unen otros del componente Loa-San Pedro, como por ejemplo la cerámica Dupont (DUP), distintiva del período anterior y que se proyecta en el Tardío. Lo mismo se infiere del fechado por termoluminiscencia que obtuvimos de un fragmento Dupont de una pieza no restringida del sitio (Uribe et al. 2004) (cuadrícula K7, nivel 8), que arrojó $1455^{ \pm} 50$ DC (UCTL 1717). Esta fecha dice relación con otras dataciones de este tipo, también tardías, del Loa Medio y del poblado de Quinchamale, en el Alto Loa (Berenguer et al. 1986: 47). Al respecto, se señala que el tipo Dupont después del 1200 DC baja su producción, pero continúa manufacturándose en época incaica (Berenguer et al. 1986: 48; Uribe 2002: 15). Queda así de manifiesto la continuidad de las expresiones culturales atacameñas en la MLT durante el Tardío, junto a cerámica inca local circumpuneña occidental y los fragmentos incaicos del interior de la mina, inexactamente determinados como Copiapó por Iribarren (1972-1973: 277, 279).

Probablemente, en las postrimerías del Intermedio Tardío y los albores del Tardío no se habría producido en la MLT una disminución de las actividades extractivas, artesanales y domésticas en el sitio, debido a que el sello atacameño del Intermedio Tardío continúa. Sobre el particular, no podemos medir la injerencia incaica por el menor porcentaje de cerámica inca local atacameña en el sitio y relacionarla directamente con una merma del quehacer minero lapidario y ocupacional en la MLT, puesto que tipos cerámicos del Intermedio Tardío se prolongan hacia tiempos tardíos (Uribe 2002). De esta manera, la explotación atacameña de la mina y su espacio adyacente de trabajo habría proseguido con absoluta normalidad e intensidad en el Tardío, sin impedir la incorporación del sitio a las normativas incaicas, si bien esto no conlleva cambios substanciales dentro del trabajo minero lapidario precedente.

En esta dirección, y por factores sociopolíticos impulsados desde el foco de poder atacameño (Loa-San Pedro), en conjunto con la activación de las nuevas dinámicas culturales incaicas, que están vinculadas con las poblaciones de Atacama (Uribe 2002: 27), se habría mantenido el abastecimiento al enclave de la MLT. Ahora con un manejo incaico de las rutas caravaneras previas (Núñez y Dillehay 1995: 128), continuando la generación de adornos en el sitio, fundamentalmente dirigidos hacia los núcleos tardíos nortinos. Aun tomando en cuenta esto, los incas no intervienen el espacio concreto de la MLT, pero síllevan a cabo una anexión efectiva y simbólica, tanto de la formación orográfica donde se emplaza la mina, el cerro Indio Muerto, como del sitio mismo. Dentro del Despoblado de Atacama, entre el extremo sur del salar homónimo y el valle de Copiapó, corresponde al único cerro que es sumado al trazado longitudinal de la ruta inca, implementada sobre caminos preexistentes.

La integración del cerro en cuestión al Qhapaq Ñan está vinculada a su riqueza mineral (turquesa, cobre y otros), conocida desde épocas preincaicas por las comunidades atacameñas, además de sus probables connotaciones simbólicas, unidas a aspectos sociales y económicos. Cabe mencionar que: "Para tiempos inkaicos, las montañas que albergaban depósitos metalíferos eran especialmente veneradas y recibían sacrificios y ofrendas [...] Las propias minas se consideraban huacas, es decir, lugares sagrados de extremo poder" (González, L. 2004: 52). En 2009 realizamos una prospección a la cima existente del cerro Indio Muerto, a $3222 \mathrm{msnm}$, sin detectar evidencias de algún adoratorio, situación tal vez derivada de la existencia del cráter artificial del cerro, originado por la gran minería del sector.

Por lo tanto, creemos que la vinculación incaica de la MLT, por medio de un empalme caminero (ver Figura 3) a la vía de comunicación inca del cerro Indio Muerto, más que activarse por un propósito económico, el cual no negamos, respondería a la fuerza simbólica del lugar y del cerro. Aunque la MLT carece de una bodega tardía al contrario de El Abra, en el curso superior del Loa (Salazar 2008: 58), como asimismo de construcciones pircadas de patrón incaico (Gasparini y Margolies 1980; Hyslop 1984, 1990; Kendall 1976; Raffino 1981; entre otros), que sí se encuentran en bajo número fuera de El Salvador, relacionadas con el Qhapaq Ñan, la definición del significativo camino inca denota y connota al cerro y la mina preexistente como propiedad del Inka. Pese a 
que la MLT no cuenta con evidencias que hagan presumir un aumento de su producción -aunque no baja con relación al Intermedio Tardío-, como tradicionalmente se asume con el vínculo entre ocupación inca y distritos mineros. Nos parece que la angosta huella (menor a 0,50 $\mathrm{m}$ de ancho) del empalme caminero del sitio fue activada en época inca, debido a que sus rasgos morfológicos son comunes a la vía tardía del cerro.

A esto se suma un espacio ritualizado en un abra (Nielsen 1997; Núñez 1999), a más de $2 \mathrm{~km}$ al suroeste de la MLT, seguramente de origen preincaico, en el sitio Sal 6-7-8, inmediato al trazado vial del cerro Indio Muerto. Presenta depositación de ofrendas de mineral molido proveniente de la MLT (Novajas 2004), cuentas de turquesa, preformas de cuentas, conchas molidas, líticos, martillos líticos, fragmentos de cerámica del Intermedio Tardío y Tardío circumpuneño, Diaguita Inca, un fragmento distal de un objeto de cobre desconocido, entre otros, coincidiendo con un comportamiento del ritualismo caminero y minero previo al Inka (Berenguer et al. 2005; Nielsen 1997; Núñez 1999), pero que en este caso exhibe una acentuada utilización durante el Tardío. También se encuentra en ese lugar un bloque rocoso con grabados de dos figuras antropomorfas y otras geométricas, realizadas al parecer con un instrumento metálico.

Cerámica Diaguita Inca, otro tipo tardío o foráneo no fue detectado en la MLT. Esto se contrapone con los hallazgos en el tramo de camino inca ubicado en el cerro Indio Muerto, donde recuperamos alfarería Diaguita Inca, Inca Cusqueña, Inca-La Paya y Saxamar (González et al. 2010: 74). Si bien estos indicadores se deben en gran parte a una variada circulación de objetos en el camino, definitivamente no se encuentran en el sitio, reforzando la exclusiva identidad atacameña tardía de la MLT. Esta situación pone de manifiesto una posible restricción sobre la entrada y salida de personas, productos e insumos desde y hacia el sitio, por medio del empalme caminero inca, resguardando el acceso a la mina y al taller lapidario. Similar característica es constatada en otra clase de talleres artesanales tardíos, que presentan una ubicación "protegida" en determinados sitios incas (Bárcena y Román 1986-1987: 64). De allí que para nosotros primaría en la MLT y en el cerro Indio Muerto una dimensión simbóli$\mathrm{ca}$, tomando en cuenta que el camino que los une posee un carácter eminentemente performativo (sensu Turnbull
2007: 143), que va más allá de una dimensión meramente económica o logística. En este sentido, el camino inca testimonia y vincula experiencialmente el mundo fuera del Cusco con el centro del poder del Tawantinsuyu (Kaulicke 2004: 337).

Con respecto a los testimonios Diaguita Inca en la comuna de Diego de Almagro, se circunscriben al Qhapaq Ñan longitudinal y sitios asociados, como también a yacimientos camineros tardíos de la puna, presentes en la ruta transversal que conectaría este sector con Finca de Chañaral y Argentina (González y Castells 2010), estando ausentes por ahora registros diaguita en contextos culturales previos al Inka en el espacio comunal. De modo que componentes Diaguita Inca ingresan a la región de Atacama por medio de la ruta incaica que se proyectaría al sur de Copiapó, uniendo los valles subsiguientes (Stehberg 1995). Se cuenta con cerámica Diaguita Inca al sur de Quinta Los Chañares (Contreras com. pers. 2015), en la ruta que uniría este pequeño oasis con Finca de Chañaral, donde también se ha reportado (Cervellino y Sills 2001: 136; Uribe et al. 2010). A su vez, en un tramo vial de $600 \mathrm{~m}$ lineales inmediatamente al norte de Inca de Oro, correspondiente a la continuidad de la ruta del Qhapaq Ñan longitudinal proveniente de Finca de Chañaral, se determinaron en un contexto de tránsito cerámica Diaguita Inca e Inca Local del valle de Copiapó (Correa 2010).

Complementariamente, en el oasis de Finca de Chañaral, desde contextos tardíos trabajados por el equipo de la Universidad de Chile (Proyecto Qhapaq Nan-CMN), se lograron dataciones por termoluminiscencia: $1430 \pm 60$ DC (UCTL 2062) (sondeo 4, nivel III, cerámica inca); y 1470 $\pm_{50}$ DC (UCTL 2060) (sondeo 3, nivel I, cerámica inca interior). ${ }^{13}$ Estas fechas grafican situaciones contemporáneas con la ocupación atacameña tardía de la MLT y una presencia incaica reiterada. Sobresale el sondeo 4 y unidades adyacentes, que evidencian un posible contexto habitacional tardío, identificándose restos óseos de llamas, guanacos y vicuñas (Uribe et al. 2010). De esta cuadrícula se obtuvieron dos fechados radiocarbónicos convencionales de huesos de camélidos (Proyecto Qhapaq Nan-CMN), el primero del nivel I con $380 \pm 20$

13 Existen otros fechados por termoluminiscencia de los sondeos 3 y 4 que nos generan dudas sobre su asignación tipológica, por lo cual no son considerados. 
AP, o cal. DC 1477-1627 (UGAMSo5971); y el segundo del nivel II con 430 \pm 20 AP, o cal. DC 1449-1503 (UGAMSo5972).14 Sin duda, este oasis constituyó un punto obligado del paso de las caravanas tardías por la ruta del Qhapaq Ñan, que hacia el norte comunicaba con la quebrada de la Sal y el "Tambo" homónimo. De este sitio obtuvimos un fechado por termoluminiscencia que

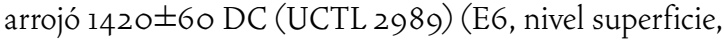
cerámica Diaguita Inca), coincidente con otras dataciones tardías de la comuna y que da cuenta de la circulación de cerámica Diaguita Inca. Prosiguiendo en dirección norte, el camino se dirige hacia el cerro Indio Muerto y la MLT, por la reconocida ruta incaica longitudinal (González 2007, 2013, 2017; González y Castells 2011; González y Westfall 2010; Westfall y González 2009; Westfall et al. 2008).

\section{* Comentarios finales y conclusiones}

El trabajo arqueológico efectuado en el sitio nos permite plantear la utilización prolongada en el tiempo de un patrón tecnológico eficiente sobre la explotación de la mina lapidaria y la consiguiente elaboración de cuentas líticas (Contreras 2004). Este patrón fue iniciado por grupos del Formativo atacameño, desarrollado en tiempos Ánimas, con la adición en términos artesanales de las figurillas zoomorfas (trozos líticos pulimentados), y ampliado a contar del Intermedio Tardío, mediante una mayor sistematización minera, que destaca la habilitación de una cancha de chancado en la terraza 1 y una profusa ocupación habitacional preferente en la terraza 2. De este modo, fue posible reconocer la existencia de una fuente directa de obtención de turquesas, minerales y arcillas en el lugar (mina), junto a la probable implementación de talleres (primario y secundario) dedicados a la elaboración de cuentas líticas (Rees 1999), en ambas terrazas del sitio, preferentemente abocados al trabajo de la turquesa.

Uno de los instrumentos fundamentales del patrón tecnológico artesanal lapidario, e indispensables para el reconocimiento de un taller secundario, son los perforadores y microperforadores líticos (Rees 1999), recuperándose 518 ejemplares en la MLT. Están presentes desde tiempos formativos en el sitio, luego en la ocupación

14 Las fechas calibradas fueron calculadas usando la curva SHCal 13 (Hogg et al., 2013) y el programa Calib 7.0.2 (Stuiver y Reimer 1993). Agradecemos la colaboración de José Francisco Blanco.
Ánimas y continúan en uso hasta la acentuada ocupación atacameña a partir del $900 \mathrm{DC}$, registrándose una frecuente confección (Contreras 2004). De esta forma, la tradición minera tecnológica lapidaria y artesanal de la MLT que se inicia en el Formativo, obedece a la conjunción de varios factores socioeconómicos. Entre ellos encontramos los requerimientos de las sociedades aldeanas de recursos económicos y simbólicos, el empleo de los circuitos de movilidad caravanera (Castro et al. 2016), y el desarrollo minero lapidario en el ámbito circumpuneño. Este trabajo cuenta con antecedentes en el Arcaico, pero una mayor acentuación en el Formativo (Carrasco 2002; Núñez 2006a, 2006b; Rees 1999; Rees y De Souza 2004; Soto 2010), y prosigue hasta etapas tardías del desarrollo atacameño, con distintos énfasis (GarcíaAlbarido 2007; Núñez 1999; Salazar 2002).

El alto número de perforadores y microperforadores líticos sugiere una confección local de cuentas de collar en la MLT. Esta relación la presume Carrasco (2002: 40-41) en el sitio Formativo Qui-49 (Quillagua). Para el Formativo Tardío de la subregión del río Salado en el Loa Superior, se asocia equivalentemente la producción especializada de microperforadores con una industria de cuentas líticas (Rees y De Souza 2004: 463). Por otra parte, la exigua frecuencia de cuentas de collar líticas finiquitadas de la MLT - solo dos ejemplares de la terraza 2 y otros dos de recolección superficial-, insinúa una salida de estos objetos desde el sitio. En este tenor, la segunda categoría instrumental en importancia cuantitativa de la MLT, los trozos líticos pulimentados, luego de los perforadores y microperforadores líticos, sustentan, de igual modo, la orientación artesanal especializada en torno a la fabricación de adornos, la principal actividad del sitio a lo largo del tiempo (Contreras 2004).

A partir de la información analizada, en la MLT estaría presente el proceso completo del trabajo minero lapidario (sensu García-Albarido 2007), desde la etapa de extracción, selección, reducción y limpieza de nódulos, su transformación en núcleos y matrices, hasta la definición de adornos como cuentas, pendientes y figurillas, especialmente en los talleres lapidarios de las terrazas del sitio. Por su parte, en el interior de la mina las labores no se limitaban a un trabajo extractivo y de limpieza de nódulos, al igual que en las terrazas 1 y 2 , sino también a actividades artesanales, domésticas y ceremoniales, por la existencia de variados 
artefactos y productos, ya explicitados. Iribarren (19721973: 269) identifica un "lugar de vivienda" en el plano del interior de la MLT. El trabajo de confección de cuentas en el sitio involucró igualmente a las conchas marinas como materia prima, con mayor acentuación durante el Intermedio Tardío, pero representando una tecnología tradicional en el sitio (Lucero et al. 2010).

Las disturbaciones sucesivas dificultaron la identificación de espacios segregados, culturalmente hablando, en el sitio, salvo por los alcances referidos en el texto. Asimismo, constatamos la ausencia de construcciones fortificadas, lo que indicaría la existencia de un espacio productivo abierto y no restringido, propiciando una coexistencia pacífica entre los grupos culturales que llegaron a explotar la MLT, especialmente al final de la ocupación Ánimas y los inicios del Intermedio Tardío atacameño. Sin embargo, también podemos interpretar que los atacameños del Intermedio Tardío llevaron a cabo una ocupación intensiva con numerosos grupos familiares, desmantelando el posible asentamiento Ánimas del lugar e implicando así acciones coercitivas, tendientes a lograr una rápida apropiación del sitio, seguramente, de gran contenido simbólico.

Desde la óptica circumpuneña, la MLT se menciona para entender la actividad minera, las redes caravaneras y los procesos culturales durante el Período Intermedio Tardío atacameño (Castro et al. 2016: 277; Salazar 2012: 214; Salazar et al. 2013: 86-87), representando una de las evidencias de la consolidación de la actividad minera atacameña en este tiempo (Salazar et al. 2013: 87). Esta ocupación, la más conspicua del sitio y sin componentes culturales Copiapó, testimonia distinciones que no se condicen con un desarrollo cultural unilineal prehispánico estructurado desde la secuencia maestra del valle de Copiapó, la cual se ha generalizado para toda la región de Atacama. De la misma manera, no pretendemos extender la situación de la MLT al espacio regional, solo la vinculamos a un específico espacio, la comuna de Diego de Almagro, con diferencias locales abordadas en este trabajo. Por lo tanto, y de acuerdo a los datos analizados, el noreste de la región de Atacama expresa una diversidad cultural, no asignable por completo al ámbito circumpuneño o al norte semiárido. En suma, estos aspectos especifican un territorio internodal con sus propias dinámicas culturales.
En concreto, los trabajos emanados de la MLT proporcionan apreciable información para contrastar la data arqueológica de otros lugares de la comuna, del área circumpuneña y de la región de Atacama. No obstante, entendemos que corresponde por ahora a un solo sitio en una zona con inicial investigación arqueológica, pero que desde la óptica del registro internodal en el espacio que nos preocupa, presenta relevantes y singulares ocupaciones culturales diacrónicas. Por ende, no puede asimilarse al campamento minero con ocupaciones intermitentes de Chu-2 (Núñez 2006a: 212-213), o definirse como los campamentos mineros del sector de Cachiyuyo de Llampos, más próximos a Copiapó (Garrido 2016). Menos circunscribirlo solo como un sitio extractivo internodal (Nielsen 2006:35), sino más bien como un asentamiento productivo y artesanal lapidario, con una ocupación prolongada de un recurrente y preeminente sello atacameño -asociada a un cercano cementerio-, que también posee referentes Ánimas. Desde nuestra perspectiva, la MLT se define como un enclave productivo lapidario y colonia a partir del Intermedio Tardío.

Debido a las características del emplazamiento del sitio en el cerro Indio Muerto, su anexión por un empalme caminero al Qhapaq Ñan longitudinal, la mantención del acentuado trabajo atacameño en el Tardío y la significación del recurso minero lapidario como potencial simbólico, consideramos que el cerro y la mina podrían corresponder a una wak'a minera de tiempos incaicos (sensu Salazar et al. 2013). Aunque no se encuentra arquitectura de patrón inca, como en otros sitios productivos mineros incaicos en Chile (Cantarutti 2013), pero si otra clase de evidencias rituales tardías en el cerro, relacionadas con la mina, anteriormente explicitadas.

La preocupación del Inka por el trabajo lapidario de cuentas, adornos y objetos rituales (illas, platos y figuras de piedra, entre otros), se expresaría en tres modalidades. En primer lugar, se aprecia la activación incaica de talleres próximos a la fuente de aprovisionamiento, como en el sitio Cogotí 18 (Looser 1960), al interior de la región de Coquimbo, Chile, correspondiente a un taller lapidario de combarbalita (Stehberg 1995: 82). ${ }^{15}$ En

15 Este sitio carece de estudios sistemáticos, aunque se define como incaico desde Cornely (1956: 151-152, 154). Se han reportado estructuras, varios platos de piedra (circulares e ictiomorfos), figuras y otros objetos (Looser 1960). 
segundo lugar, es notoria una concentración de artesanos trasladados que inician una tradición lapidaria artesanal en un sitio con ocupación local previa, como por ejemplo en las casas-talleres (Otero 2015) lapidarios del Pucará de Tilcara, quebrada de Humahuaca, en el Noroeste argentino, donde se elaboraban objetos, adornos y piezas de uso ritual, utilizando alabastro, ónix, caliza, entre otros (Krapovickas 1981-1982; Otero 2015), contándose en una casa-taller con perforadores líticos (Krapovickas 1964: 142, 144; Otero 2015: 9). Aquí se encuentran artesanos especialistas tributarios en un yacimiento con administración inca, como en sitios similares o de diferentes funciones en el Tawantinsuyu, dedicados al trabajo en diversas materias primas (Alconini 2013: 278; Earle 1994: 446; Hocquenghem y Peña 1994; Williams y Lorandi 1986; entre otros).

Mientras que, en tercer lugar, el Inka mantiene el quehacer tecnológico lapidario preexistente en focos locales productivos y artesanales eficientes, donde es manifiesta una fuerza de trabajo especializada (Llagostera 1976: 46). En estos sitios no se evidencia una intervención del espacio con asentamientos y construcciones distintivamente incas, pero están integrados a un domino incaico de mayor alcance, junto con estar inmediatos o cercanos al camino inca; al igual que los casos anteriores. Lo anterior no se limita al trabajo lapidario, sino también se ha comprobado en otras áreas productivas estatales, como la agrícola en el extremo septentrional del Noroeste argentino (Casabindo) (Albeck 2016). A nuestro entender, esto acontece en la MLT durante el Tardío. El Estado Inca no necesitó trasladar grupos foráneos al foco productivo lapidario, pues ya estaban presentes las agrupaciones familiares de mineros-caravaneros y artesanos especialistas atacameños. En consecuencia, consideramos que el Inka respeta y aprovecha esta situación, las probables alianzas con las jefaturas atacameñas nortinas y el conocimiento tecnológico minero lapidario precedente, tal como ocurre en varios puntos de la circumpuna occidental sobre el desarrollo minero atacameño (Núñez 2006a: 225; Salazar 2012: 217; Salazar et al. 2013).

Por consiguiente, la ocupación inca del territorio desértico e internodal de la comuna de Diego de Almagro, no responde exclusivamente a un evidente criterio de constatación de materialidad tardía (Qhapaq Ñan, adoratorios, arte rupestre, arquitectura, objetos muebles, entre otros) que conforma paisajes incaicos, sino también a acciones implícitas de un dominio simbólicamente efectivo de un amplio espacio geográfico. Esta dinámica cultural se habría implementado mediante alianzas y pactos, reconociéndose bajo la omnipresencia del Inka y la concentrada fuerza de trabajo local, con su tradición tecnológica en cuanto a la lapidaria en la MLT, sin mediar en este proceso acciones coercitivas. Todo ello en un contexto tardío culturalmente diverso a nivel local y regional, hoy en ciernes respecto a su conocimiento arqueológico.

Agradecimientos A División Salvador de Codelco y al Consejo de Monumentos Nacionales. Agradecemos las gentilezas de Claudia Prado, Valentina Figueroa, Roxana Seguel, Carole Sinclaire, Lautaro Núñez, José Berenguer, Lino Contreras, Mario Vásquez, Juan García, Andrés Troncoso, Francisco García-Albarido, Ángel Durán, José F. Blanco, César Méndez y Daniel Pascual. Un reconocimiento especial a los colegas y analistas que colaboraron en el rescate del sitio MLT. A los evaluadores anónimos nuestro agradecimiento, ya que sus observaciones ayudaron a reorganizar y enriquecer este trabajo.

Nota "Mina Las Turquesas: lapidaria, secuencia alfarera prehispánica e interrelaciones culturales en un espacio internodal del desierto de Atacama, Chile", publicado en Estud. atacam., ahead of print Epub 09-Jun-2017, http:// dx.doi.org/10.4067/S0718-10432017005000007, con fecha 07 de noviembre de 2017, se agregó como co-autor a Catherine Westfall, dada su concreta participación en nuestro equipo de trabajo el año 2004, en el marco del rescate del sitio, que se efectuó bajo los lineamientos del Ord. $N^{\circ} 2376$ del Consejo de Monumentos Nacionales. A raíz de lo anterior, en los agradecimientos se efectuaron cambios menores. 


\section{* Referencias citadas}

ALBECK, M. E. 2016. Producción y lógica de la red vial incaica en el extremo septentrional del NOA. Arqueología 22 (1): 61-79.

ALCONINI, S. 2013. El territorio Kallawaya y el taller alfarero de Milliraya: evaluación de la producción, distribución e intercambio interregional de la cerámica inka provincial. Chungara. Revista de Antropología Chilena 45(2): 277-292.

BÁRCENA, J. R. y A. ROMÁN. 1986-1987. Funcionalidad diferencial de las estructuras del tambo de Tambillos: resultados de la excavación de los recintos 1 y 2 de la unidad A del sector III. Anales de Arqueología y Etnología 41/42: 7-81.

BELMAR, C. y L. QUIROZ. 2004 Ms. Informe arqueobotánico Mina Las Turquesas.

BERENGUER, J., A. DEZA, A. ROMÁN y A. LLAGOSTERA. 1986. La secuencia de Myriam Tarragó para San Pedro de Atacama: Un test por termoluminiscencia. Revista Chilena de Antropología 5: 17-54.

BERENGUER, J., I. CÁCERES, C. SANHUEZA y P. HERNÁNDEZ. 2005. El Qhapaqñan en el Alto Loa, norte de Chile: un estudio micro y macromorfológico. Estudios Atacameños 29: 7-39.

BRAUDEL, F. 2002. Las ambiciones de la historia. Editorial Crítica, Barcelona.

CANTARUTTI, G. 2013. Mining under inca rule in north-central Chile: The Los Infieles mining complex. En Mining and Quarrying in the Ancient Andes: Sociopolitical, Economic and Symbolic Dimensions, N. Tripcevih y J. K. Vaughn (Eds.), pp. 185-211. Springer, New York.

CARRASCO, C. 2002. Las industrias líticas de Quillagua durante el período Formativo, en el contexto del Norte Grande. Estudios Atacameños 22: 33-57.

CASES, B. 2004 Ms. Informe textil Mina Las Turquesas.

CASTELLS, C., C. GONZÁLEZ y C. WESTFALL. 2010a. Endoparasitismo y dieta en dos poblaciones atacameñas: análisis de coprolitos de los sitios Mina Las Turquesas y Cementerio Regimiento Chorrillos. En Actas del XVII Congreso Nacional de Arqueología Chilena, pp. 759-768. UACH, Valdivia.

CASTELLS, C., C. GONZÁLEZ y C. WESTFALL. 2o1ob. Aplicación de una metodología química de análisis de fósforo en los sitios Mina Las Turquesas y Cementerio Regimiento Chorrillos, Chile. En Actas del ХVII Congreso Nacional de Arqueología Chilena, pp. 769-778. UACH, Valdivia.
CASTILLO, G. 1989. Agricultores y pescadores del norte chico. El Complejo Las Ánimas (800 a 1.200 d.C.). En Prehistoria. Culturas de Chile, J. Hidalgo, V. Schiappacasse, H. Niemeyer, C. Aldunate e I. Solimano (Eds.), pp. 265-276. Editorial Andrés Bello, Santiago.

CASTILLO, G. 1998. Los períodos Intermedio Tardío y Tardío: desde la Cultura Copiapó al dominio Inca. En Culturas prehistóricas de Copiapó, H. Niemeyer y M. Cervellino (Eds.), pp. 163282. MRA, Copiapó.

CASTILLO, G. e I. KUZMANIC. 1981. Registro de colecciones inéditas del Complejo Cultural El Molle (Trabajo descriptivo). Boletín Museo Arqueológico La Serena 17: 122-221.

CASTRO, V., J. BERENGUER, F. GALLARDO, A. LLAGOSTERA y D. SALAZAR. 2016. Vertiente occidental circumpuneña. Desde las sociedades posarcaicas hasta las preincas (ca. 1.500 años a.C. a 1.470 d.C.). En Prehistoria en Chile. Desde sus primeros habitantes hasta los Incas, F. Falabella, M. Uribe, L. Sanhueza, C. Aldunate y J. Hidalgo (Eds.), pp. 239-283. Editorial Universitaria y SCHA, Santiago.

CERVELLINO, M. y N. GAETE. 20oo. Asentamientos del período Intermedio Tardío y Tardío en el sitio "El Castaño", Río Jorquera, valle de Copiapó-Chile. Contribución Arqueológica 5: 641-653.

CERVELLINO, M. y N. SILLS. 2001. El arte rupestre de los sitios Finca de Chañaral y Quebrada de Las Pinturas, región de Atacama. En Segundas Jornadas de Arte y Arqueología, J. Berenguer, L. Cornejo, F. Gallardo y C. Sinclaire (Eds.), pp. 134-151. MCHAP, Santiago.

CONTRERAS, L. 2004 Ms. Análisis del conjunto lítico Mina Las Turquesas.

CORNEJO, L. 2014. Sobre la cronología del inicio de la imposición cuzqueña en Chile. Estudios Atacameños. Arqueología y Antropología Surandinas 47: 101-116.

CORNELY, F. 1956. La cultura Diaguita chilena y cultura de El Molle. Editorial del Pacífico, Santiago.

CORREA, I. 2010 Ms. Informe de análisis cerámico. Tramo Qhapaq Ñan - Inca de Oro. Anexo 4 Informe final medidas de compensación en el marco del proyecto Reposición Ruta C-17, sector Inca de Oro - Diego de Almagro, Tramo KM. 60.00o- KM. 123.592, Mario Vásquez y Juan García, Santiago. 
CHONG, G. 2012. Historias del paisaje. En Atacama, C. Aldunate (Ed.), pp. 24-53. MCHAP, Santiago.

DE UGARTE, M., C. WESTFALL y C. GONZÁLEZ. 2010. Análisis morfofuncional de los restos de maderas en la Mina Las Turquesas, región de Atacama. En Actas del XVII Congreso Nacional de Arqueología Chilena, pp. 1213-1223. UACH, Valdivia.

DURÁN, A. 2008 Ms. Informe descriptivo. Material obtenido en túmulos en Finca de Chañaral.

EARLE, T. 1994. Wealth finance in the inka empire: evidence from the Calchaquí valley, Argentina. American Antiquity 59(3): 443-450.

GAETE, N. y M. CERVELLINO. 2000. Asentamientos habitacionales de la Cultura Copiapó en el río Jorquera, Formativo del río Copiapó, región de Atacama, Chile. Contribución Arqueológica 5: 607-629.

GARCÍA-ALBARIDO, F. 2007 Ms. Umiñas en Atacama: aproximación a la lapidaria durante el período Intermedio Tardío y Tawantinsuyu. Informe de práctica profesional, Departamento de Antropología, UCH, Santiago.

GARRIDO, F. 2007 Ms. El camélido sagrado y el hombre de los valles. Una aproximación a la cultura Copiapó a partir de la alfarería. Memoria para optar al título de Arqueólogo. UCH, Santiago.

GARRIDO, F. 2016. Rethinking imperial infrastructure: A bottomup perspective on the Inca Road. Journal of Anthropological Archaeo$\log y$ 43: 94-109.

GASPARINI, G. y L. MARGOLIES. 1980. Inca architecture. Indiana University Press, Bloomington and London.

GIMÉNEZ, G. y C. HÉAU LAMBERT. 2007. El Desierto como territorio, paisaje y referente de identidad. Culturales 5(3): 7-42.

GONZÁLEZ, C. 2007. Qhapaq Ñan en el extremo meridional del Despoblado de Atacama, Chile. En Actas del XVI Congreso Nacional de Arqueología Argentina, pp. 511-518. UNJu, San Salvador de Jujuy.

GONZÁLEZ, C. 2008. Prehistoria de Diego de Almagro: descubriendo nuestro pasado más lejano. En II Encuentro de Historia Comunal, pp. 33-61. IMDA, Diego de Almagro.

GONZÁLEZ, C. 2013 Ms. Caracterizaciones, consideraciones teóricas y nuevas propuestas sobre la arqueología del Qhapaq Ñan. Tesis para optar el grado de Magíster en Antropología con mención en Arqueología, UCN y UTA, Arica.

GONZÁLEZ, C. 2017. Arqueología vial del Qhapaq Ñan en Sudamérica: análisis teórico, conceptos y definiciones. Boletín del $M u-$ seo Chileno de Arte Precolombino 22(1). En prensa.
GONZÁLEZ, C. y C. CASTELLS. 2010. Qhapaq Ñan y la ocupación incaica de la Puna Atacameña (III Región, Chile). Nuevos registros y perspectivas. En Actas del XVII Congreso Nacional de Arqueología Argentina, pp. 1315-1320. UNC, INCIHUSA-CONICET, Mendoza.

GONZÁLEZ, C. y C. CASTELLS. 2011. El Camino del Inka en el Desierto Meridional de Atacama. La ruta sagrada de los minerales. En III Encuentro de Historia Local, G. Mánquez, G. Cortés y C. González (Eds.), pp. 13-27. IMDA, MRA y GORE, Diego de Almagro.

GONZÁLEZ, C. y C. WESTFALL. 2005. Consideraciones sobre la prehistoria de Atacama: El Salvador y sus aportes locales e interregionales. Boletín de la Sociedad Chilena de Arqueología 38: 53-70.

GONZÁLEZ, C. y C. WESTFALL. 2008. Atacameños en El Salvador: nuevas apreciaciones sobre un fardo funerario del Cementerio Las Turquesas. Estudios Atacameños. Arqueología y Antropología Surandinas 35: 49-73.

GONZÁLEZ, C. y C. WESTFALL. 2010. Qhapaq Ñan, arquitectura vernácula y del Inka en El Salvador, región de Atacama. En Actas del XVII Congreso Nacional de Arqueología Chilena, pp. 887-897. $\mathrm{UACH}$, Valdivia.

GONZÁLEZ, C., C. WESTFALL y C. CASTELLS. 2010. Investigación, conservación y puesta en valor del patrimonio arqueológico asociado al proyecto minero Damiana, El Salvador, región de Atacama. Boletín Museo Regional de Atacama 1: 63-87.

GONZÁlEZ, C., C. CASTELLS y A. PACHECO. 2009 Ms. Informe final Cementerio Las Turquesas, El Salvador.

GONZÁLEZ, L. 2004. El arte del cobre en el mundo andino. MCHAP, Santiago.

HOCQUENGHEM, A. M. y M. PEÑA. 1994. La talla del material malacológico en Tumbes. Bulletin de l'Institut Français d'Études Andines 23(2): 209-229.

HOGG, A., H. QUAN, P. BLACKWELL, N. MU NIU, C. BUCK, T. GUILDERSON, T. HEATON, J. PALMER, P. REIMER, R. REIMER, C. TURNEY and S. ZIMMERMAN. 2013. Shcali3 southern hemisphere calibration, $0-50.000$ years cal. BP. Radiocarbon 55(4): 1889-1903.

HYSLOP, J. 1984. The Inka road system. Academic Press, Orlando.

HYSLOP, J. 1990. Inka settlement planning. University of Texas Press, Austin.

IRIBARREN, J. 1972-1973. Una mina de explotación incaica: El Salvador-Provincia de Atacama. En Actas del VI Congreso de Arqueología Chilena, pp. 267-283. UCH, Santiago. 
IRIBARREN, J. y H. BERGHOLZ. 1972-1973. El camino del Inca en un sector del norte chico. En Actas del VI Congreso de Arqueología Chilena, pp. 229-266. UCH, Santiago.

KAULICKE, P. 2004. Identidad, etnicidad e imperios: algunas reflexiones finales. Boletín de Arqueología PUCP 8: 325-357.

KENDALL, A. 1976. Descripción e inventario de las formas arquitectónicas Inca. Revista del Museo Nacional 42: 13-96.

KRAPOVICKAS, P. 1964. Un taller de lapidario en el Pucará de Tilcara. Runa 9: 137-151.

KRAPOVICKAS, P. 1981-1982. Hallazgos incaicos en Tilcara y Yacoraite (Una reinterpretación). Relaciones de la SociedadArgentina de Antropología XIV(2): 67-80.

LATORRE, E. 2009 Ms. De adornos y herramientas nacidos del fuego: una caracterización del trabajo de metales en la Cultura Diaguita (ca. 900-1536 d.C.). Memoria para optar al título de Arqueólogo. UCH, Santiago.

LOOSER, G. 1960. Esculturas de piedra de aspecto "chileno" halladas en el Cuzco. Revista Universitaria. Anales de la Academia Chilena de Ciencias Naturales XLIV-XLV: 182-186.

LUCERO, M., C. GONZÁLEZ y C. WESTFALL. 2010. Artefactos conquiológicos del sitio Mina Las Turquesas: el trabajo de la concha en un asentamiento minero lapidario de El Salvador, región de Atacama, Chile. En Actas del XVII Congreso Nacional de Arqueología Chilena, pp. 253-266. UACH, Valdivia.

LLAGOSTERA, A. 1976. El Tawantinsuyo y el control de las relaciones complementarias. En Actes du XLIIe Congrès International des Américanistes, pp. 39-50. Fondation Singer-Polignac, Paris.

MARTÍNEZ, J. L. 1990. Interetnicidad y complementariedad en el Altiplano Meridional: el caso Atacameño. Andes 1: 11-30.

MATTOZZI, I. 2014. Historia y epistemología de las ciencias. ¿Quién le tiene miedo a la geohistoria? Enseñanza de las Ciencias Sociales 13: 85-105.

MOSCOSO, R. y C. MPODOZIS. 1988. Estilos estructurales en el norte chico de Chile (28-31 $\mathrm{S})$, regiones de Atacama y Coquimbo. Revista Geológica de Chile 15(2): 151-166.

NIELSEN, A. 1997. El tráfico caravanero visto desde La Jara. Estudios Atacameños 14:339-371.

NIELSEN, A. 2006. Estudios internodales e interacción interregional en los Andes circumpuneños: teoría, método y ejemplos de aplicación. En Esferas de interacción prehistóricas y fronteras nacionales modernas: los Andes surcentrales, H. Lechtman (Ed.), pp. 29-62. IEP e IAR, Perú.
NIELSEN, A. 2007. Bajo el hechizo de los emblemas: políticas corporativas y tráfico interregional en los Andes circumpuneños. En Producción y circulación prehispánicas de bienes en el sur andino, A. Nielsen, M. C. Rivolta, V. Seldes, M. M. Vásquez y P. H. Mercolli (Comps.), pp. 393-411. Editorial Brujas, Argentina.

NIELSEN, A. 2008. Una arqueología de los "espacios vacíos" de los Andes circumpuneños. Novedades en Antropología 59:3-6.

NIEMEYER, H. 1994. Pasos cordilleranos y contactos entre los pueblos del norte chico de Chile y el Noroeste argentino. En La cordillera de los Andes: ruta de encuentros, pp. 23-37. MCHAP, Santiago.

NIEMEYeR, H. 1998. El período Medio. Complejo Las Ánimas. En Culturas prehistóricas de Copiapó, H. Niemeyer y M. Cervellino (Eds.), pp. 115-162. MRA, Copiapó.

NIEMEYER, H. y M. RIVERA. 1983. El camino del Inca en el Despoblado de Atacama. Boletín de Prehistoria de Chile 9: 91-193.

NIEMEYER, H., G. CASTILLO y M. CERVELLINO. 1989. Los primeros ceramistas del norte chico: Complejo El Molle (o a 800 d.C.). En Prehistoria. Culturas de Chile, J. Hidalgo, V. Schiappacasse, H. Niemeyer, C. Aldunate y I. Solimano (Eds.), pp. 227-263. Editorial Andrés Bello, Santiago.

NIEMEYER, H., G. CASTILlO y M. CERVELLINO. 1995. Los túmulos funerarios de la Quebrada de la Puerta, valle de Copiapó, región de Atacama, Chile. En Actas del XIII Congreso Nacional de Arqueología Chilena, pp. 185-197. UA, Antofagasta.

NIEMEYER, H., M. CERVELLINO y G. CASTILLO. 1998. Culturas prehistóricas de Copiapó, H. Niemeyer y M. Cervellino (Eds.). MRA, Copiapó.

NOVAJAS, R. 2004 Ms. Análisis por difracción y fluorescencia de rayos $\mathrm{X}$ de muestras arqueológicas de El Salvador.

NÚÑEZ, L. 1987. Tráfico de metales en el área Centro-Sur Andina: factos y expectativas. Cuadernos Instituto Nacional de Antropología 12: 73-105.

NÚÑEZ, L. 1991. Cultura y conflicto en los oasis de San Pedro de Atacama. Editorial Universitaria, Santiago.

NÚÑEZ, L. 1999. Valoración minero-metalúrgica circumpuneña: menas y mineros para el Inka rey. Estudios Atacameños 18: 177-221.

NÚÑEZ, L. 2006a. La orientación minero-metalúrgica de la producción atacameña y sus relaciones fronterizas. En Esferas de interacción prehistóricas y fronteras nacionales modernas: los Andes sur centrales, $\mathrm{H}$. Lechtman (Ed.), pp. 205-251. IEP e IAR, Perú. 
NÚÑEZ, L. 2006b. Asentamientos formativos complejos en el centro-sur andino: cuando la periferia se constituye en núcleo. Boletín de Arqueología PUCP 10:321-356.

NÚÑEZ, L. y T. DILLEHAY. 1995 [1979]. Movilidad giratoria, armonía social y desarrollo en los Andes Meridionales: Patrones de Tráfico e interacción económica. UCN, Antofagasta.

OTERO, C. 2015. Distribución y consumo de cerámica inca en el Pucará de Tilcara (Quebrada de Humahuaca, Argentina). Chungara. Revista de Antropología Chilena 47 (3): 401-414.

PRADO, C. 2004 Ms. Análisis técnico cestería en espiral Mina Las Turquesas.

RAFFINO, R. 1981. Los Inkas del Kollasuyu. Editorial Ramos Americana, La Plata.

REES, CH. 1999. Elaboración, distribución y consumo de cuentas de malaquita y crisocola durante el período Formativo en la vega de Turi y sus inmediaciones, subregión del río Salado, norte de Chile. En Los tres reinos: prácticas de recolección en el cono sur de América, C. Aschero, M. A. Korstanje y P. Vuoto (Eds.), pp. 85-98. IAM, UNT, Tucumán.

REES, CH. y P. DE SOUZA. 2004. Producción lítica durante el período Formativo en la subregión del Río Salado. Chungara. Revista de Antropología Chilena, volumen especial: 453-465.

S/A. 1957. Andino 30. Semanario de los empleados y obreros de Andes Copper Mining Co. y Potrerillos Railway Co., Potrerillos.

SALAZAR, D. 2002 Ms. El complejo minero San José del Abra, II región (1450-1536 d.C.). Una aproximación a la arqueología de la minería. Tesis para optar del grado de Magíster en Arqueología. $\mathrm{UCH}$, Santiago.

SALAZAR, D. 2008. La producción minera en San José del Abra durante el período Tardío atacameño. Estudios Atacameños. Arqueología y Antropología Surandinas 36: 43-72.

SALAZAR, D. 2012. Historia de la minería indígena en Atacama. En Atacama, C. Aldunate (Ed.), pp. 198-221. MCHAP, Santiago.

SALAZAR, D., J. BERENGUER y G. VEGA. 2013. Paisajes minerometalúrgicos en Atacama y el Altiplano Sur de Tarapacá. Chungara. Revista de Antropología Chilena 45(1): 83-103.

SEGUEL, R. 1986a Ms. Informe preliminar. Algunas consideraciones sobre conservación preventiva para el material arqueológico a exhumar en "Finca de Chañaral".
SEGUEL, R. 1986b Ms. Informe de campo y de laboratorio. Conservación in situ y análisis de laboratorio para el material arqueológico proveniente del sitio "Finca de Chañaral".

SOTO, C. 2010. Tipología de cuentas de collar en la Quebrada de Tulan (Salar de Atacama): nueva línea de evidencia para la transición Arcaico-Formativo. En Actas del XVII Congreso Nacional de Arqueología Chilena, pp. 1123-1134. UACH, Valdivia.

STEHBERG, R. 1995. Instalaciones incaicas en el norte y centro semiárido de Chile. DIBAM, Santiago.

STUIVER, M. y P. REIMER. 1993. Extended ${ }^{14} \mathrm{C}$ database and revised CALIB radiocarbon calibration program. Radiocarbon $35: 215-230$.

TARRAGÓ, M. 2002. El Formativo y el surgimiento de la complejidad social en el Noroeste argentino. En Formativo sudamericano, P. Ledergerber-Crespo (Ed.), pp. 303-315. Ediciones AbyaYala, Quito.

TRONCOSO, A. y D. PAVLOVIC. 2013. Historia, saberes y prácticas: un ensayo sobre el desarrollo de las comunidades alfareras del norte semiárido chileno. Revista Chilena de Antropología 27(1): 101-140.

TRONCOSO, A., G. CANTARUTTI y P. GONZÁLEZ. 2016. Desarrollo histórico y variabilidad espacial de las comunidades alfareras del norte semiárido (ca. 300 años a.C. a 1.450 d.C.). En Prehistoria en Chile. Desde sus primeros habitantes hasta los Incas, F. Falabella, M. Uribe, L. Sanhueza, C. Aldunate y J. Hidalgo (Eds.), pp. 319-364. Editorial Universitaria y SCHA, Santiago.

TURNBULL, D. 2007. Maps narratives and trails: performativity, hodology and distributed knowledges in complex adaptive systems - an approach to emergent mapping. Geographical Research 45(2): 140-149.

URIBE, M. 1999. La alfarería inca de Caspana. Boletín de la Sociedad Chilena de Arqueología 27: 11-19.

URIBE, M. 2002. Sobre alfarería, cementerios, fases y procesos durante la prehistoria tardía del Desierto de Atacama (800-1600 DC). Estudios Atacameños 22: 7-31.

URIBE, M. 2012. La prehistoria de Atacama. En Atacama, C. Aldunate (Ed.), pp. 54-109. MCHAP, Santiago.

URIBE, M. y L. ADÁN. 2005. Arqueología e historia... cultura y evolución social en el Desierto de Atacama (900-1700 DC). En Actas del ХVI Congreso Nacional de Arqueología Chilena, pp. 263-274. Ediciones Escaparate, Concepción. 
URIBE, M. y G. CABELLO. 2009. ¿Diaguitas en el Desierto de Atacama?: circulación de cerámica y movimientos de poblaciones durante el dominio del Inka. En Actas del XV Congreso de Arqueología Argentina, pp. 105-114. UNRC, Río Cuarto.

URIBE, M. y R. SÁNCHEZ. 2016. Los incas en Chile. Aportes de la arqueología chilena a la historia del Tawantinsuyo (ca. 1.400 a 1.536 años d.C.). En Prehistoria en Chile. Desde sus primeros habitantes hasta los Incas, F. Falabella, M. Uribe, L. Sanhueza, C. Aldunate y J. Hidalgo (Eds.), pp. 529-572. Editorial Universitaria y SCHA, Santiago.

URIBE, M., G. CABELLO y L. SANHUEZA. 2004 Ms. Análisis de la cerámica de Mina Las Turquesas, El Salvador (III Región).

URIBE, M., A. TRONCOSO, M. SEPÚLVEDA y C. GONZÁLEZ. 2010 Ms. Estudio diagnóstico de situación del Qhapaq Ñan en Chile, componente difusión e investigación para las regiones de Arica-Parinacota y Atacama. Línea arqueología, informe final. Departamento de Antropología, UCH, Santiago.

VELÁSQUEZ, H. 2004 Ms. Análisis zooarqueológico Mina Las Turquesas.
WESTFALL, C. y C. GONZÁLEZ. 2009. Estudio micromorfológico de un tramo del Camino del Inka y sitios asociados, El Salvador, III Región, Chile. En Actas del XV Congreso de Arqueología Argentina, pp. 115-126. UNRC, Río Cuarto.

WESTFALL, C. y C. GONZÁLEZ. 2010. Mina Las Turquesas: un asentamiento minero lapidario en el extremo meridional circumpuneño, región de Atacama, Chile. En Actas del XVII Congreso Nacional de Arqueología Chilena, pp. 1073-1083. UACH, Valdivia.

WESTFALL, C., C. CASTELLS y C. GONZÁLEZ. 2008. Conservación arqueológica del itinerario cultural del Qhapaq Nan de El Salvador, región de Atacama. Conserva 12: 97-109.

WESTFALL, C., M. BELMAR y C. GONZÁLEZ. 2010. Aplicación geo-arqueológica de microscopía electrónica y microsonda en piezas metalográficas y líticas del Cementerio Regimiento Chorrillos de Calama. En Actas del XVII Congreso Nacional de Arqueología Chilena, pp. 835-846. UACH, Valdivia.

WILLIAMS, V. y A. M. LORANDI. 1986. Evidencias funcionales de un establecimiento incaico en el Noroeste argentino. Comechingonia, número especial: 133-148. 